\title{
Peripheral-physiological and neural correlates of the flow experience while playing video games: a comprehensive review
}

\author{
Shiva Khoshnoud ${ }^{\text {Corresp., } 1}$, Federico Alvarez Igarzábal ${ }^{1}$, Marc Wittmann ${ }^{1}$ \\ ${ }^{1}$ Institute for Frontier Areas of Psychology and Mental Health, Freiburg, Germany \\ Corresponding Author: Shiva Khoshnoud \\ Email address: khoshnoud@igpp.de
}

The flow state is defined by intense involvement in an activity with high degrees of concentration and focused attention accompanied by a sense of pleasure. Video games are effective tools for inducing flow, and keeping players in this state is considered to be one of the central goals of game design. Many studies have focused on the underlying physiological and neural mechanisms of flow. Results are inconsistent when describing a unified mechanism underlying this mental state. This paper provides a comprehensive review of the physiological and neural correlates of flow and explains the relationship between the reported physiological and neural markers of the flow experience. Despite the heterogeneous results, it seems possible to establish associations between reported markers and the cognitive and experiential aspects of flow, particularly regarding arousal, attention control, reward processing, automaticity, and self-referential processing. 
1 Peripheral-physiological and neural correlates of the

2 flow experience while playing video games: a

3 comprehensive review

4

5

6 Shiva Khoshnoud ${ }^{1 *}$, Federico Alvarez Igarzábal' ${ }^{1}$, Marc Wittmann ${ }^{1}$

$7 \quad{ }^{1}$ Institute for Frontier Areas of Psychology and Mental Health, Freiburg, Germany

8

9

10

11

12 Corresponding Author:

13 *Shiva Khoshnoud

14 Wilhelmstr. 3a, 79098 Freiburg, Germany

15 Email address: khoshnoud@,igpp.de

16

17

18

19

20

21

22

23 


\section{Abstract}

The flow state is defined by intense involvement in an activity with high degrees of concentration and focused attention accompanied by a sense of pleasure. Video games are effective tools for inducing flow, and keeping players in this state is considered to be one of the central goals of game design. Many studies have focused on the underlying physiological and neural mechanisms of flow. Results are inconsistent when describing a unified mechanism underlying this mental state. This paper provides a comprehensive review of the physiological and neural correlates of flow and explains the relationship between the reported physiological and neural markers of the flow experience. Despite the heterogeneous results, it seems possible to establish associations between reported markers and the cognitive and experiential aspects of flow, particularly regarding arousal, attention control, reward processing, automaticity, and selfreferential processing.

\section{Introduction}

What makes everyday experiences genuinely satisfying? Csikszentmihalyi (1975) introduced the concept of "flow" or "being in the zone" as an optimal state in which complete absorption in an activity is reached and is accompanied by a sense of enjoyment and apparent ease of processing. Flow is a subjective experience in which actions seem to happen effortlessly, fluently, and almost automatically. According to this theory, the clearest sign of flow is the merging of action and awareness in a way that "a person in flow is aware of his actions but not of the awareness itself” (Csikszentmihalyi, 1975, pp 38). Paradigmatic examples of flow-inducing activities include the artist who is completely immersed in the activity of creating a work of art or playing an instrument and the athlete or game player who follows clear goals and perceives a match between demands and skills. The following factors enable the flow experience, which in combination create a deep sense of enjoyment (Csikszentmihalyi, 1975, 1990; Jackson \& Eklund, 2004): 1) the balance between the level of skill and the challenges of the task, 2) clear goals of the activity, 3) clear immediate feedback of action results, 4) merging of action and awareness, 5) high concentration, 6) a sense of control over the activity, 7) a loss of selfawareness, 8) a loss of the sense of time, and 9) autotelic experience or an intrinsically rewarding perception of the activity. Among the nine key components of flow, the first three (balance between skills and challenges, clear goals, and immediate feedback) can also be understood as antecedents to or activity-related preconditions for flow; the remaining six items are characteristics of this subjective state. An optimal skill-challenge balance is considered to be the main antecedent which facilitates entering into the flow state (Csikszentmihalyi \& Csikszentmihalyi, 1992; Engeser \& Rheinberg, 2008; Fong, Zaleski, \& Leach, 2015; Keller \& Blomann, 2008). If the challenge level of the activity outweighs the skill level of the person performing it, the person will become frustrated. In contrast, if the challenge level is lower than the skill level, the person will become bored (the flow-channel model; Csikszentmihalyi, 1975, 1990). Although the skill-challenge balance is a 
62 prerequisite for the flow experience, it does not guarantee entering into the flow state. Fong et al.

63 (2015) showed that additional variables, such as age, cultural characteristics, domain of

64 application (leisure or work/educational contexts), and methodology (how the skill-challenge

65 balance is evaluated) may distinctively influence the relationship between flow and the skill-

66 challenge balance. Engeser \& Rheinberg (2008) showed that flow was still high even when the

67 demand was low in activities that were subjectively evaluated as important to succeed in.

68 Investigation of the moderating impact of personality characteristics, such as the action-state

69 orientation, revealed that individuals with a strong habitual action orientation are more sensitive

70 to modulations of the skill-challenge balance (Keller \& Bless, 2008). The likelihood of the

71 ensuing flow experience can also be altered by personality factors. A study by Ullén and

72 colleagues (2012) reported a negative correlation between flow proneness (understood as the

73 individual propensity to experience flow) and neuroticism. De Manzano et al. (2013) suggested

74 that lower trait impulsivity could facilitate the propensity to experience flow.

75 Despite such potential modulators, the relationship between the skill-challenge balance and flow

76 postulated in the flow-channel model affords an approach for experimentally manipulating flow

77 by presenting different levels of challenge. Although inducing flow under controlled laboratory

78 conditions has been considered difficult, game-based paradigms are especially promising, as: a)

79 games offer challenging tasks that require training skills and provide clear goals, as well as

80 immediate feedback (Alvarez Igarzábal, 2019; Salen \& Zimmerman, 2003), and b) the difficulty

81 level of a game can relatively easily be manipulated to achieve the skill-challenge balance. An

82 important driver of enjoyment in games comes from effectance motivation, a term coined by

83 Nacke (2012), which is the feeling of empowerment in players when they see the impact of their

84 actions. This feeling of control can be experienced when the game's challenge matches the

85 player's skills and goals and immediate feedback are provided. The experimental approaches

86 include dynamic matching of the game's difficulty level to the player's skill level (Keller \&

87 Bless, 2008; Rheinberg \& Vollmeyer, 2003) or pre-testing the participants' skills to individually

88 assign appropriate challenge levels in the game (Moller, Csikszentmihalyi, Nakamura, \& Deci,

89 2007). This can help to contrast three experimental conditions: easy, optimal, and overwhelming.

90 Rheinberg and Vollmeyer (2003) evaluated the impact of modulating the task difficulty on the

91 flow experience in two different video games, Roboguard and Pac-Man. The highest level of

92 flow was reported following those trials in which the game's difficulty was set to a medium level

93 rather than to a low or high level. A self-selected level of difficulty (autonomy) was also

94 suggested to be an important determinant of flow (De Sampaio Barros et al., 2018; Moller,

95 Meier, \& Wall, 2010). Some studies implemented an additional immersion condition, which was

96 described as the gradual process of transporting the player's mind into the virtual world by

97 manipulating factors like graphics, sound, and gameplay (Drachen, Nacke, Yannakakis, \&

98 Pedersen, 2010; Nacke, Stellmach, \& Lindley, 2011). Immersion is an important concept in

99 virtual reality (VR) and computer-gaming research and seems closely connected to flow in these

100 contexts, as both pertain to a pleasant, absorbed mental state common in gamers. However, flow 
101

102

103

104

105

106

107

108

109

110

111

112

113

114

115

116

117

118

119

120

121

122

123

124

125

126

127

128

129

130

131

132

133

134

135

and immersion can be distinguished due to subtle structural differences (for further information, please see Michailidis, Balaguer-Ballester, \& He, 2018).

Experimental flow research using computer games has important implications, such as understanding peak performance. Flow and performance seem to be closely related (Csikszentmihalyi, Abuhamdeh, \& Nakamura, 2005; Engeser \& Rheinberg, 2008; Jin, 2012; Keller \& Bless, 2008; Landhäußer \& Keller, 2012). High performance levels are typically expected during the experience of flow because frustration and boredom lead to diminished concentration and, consequently, to poor performance. It is still unclear whether flow influences performance or vice versa (De Kock, 2014; Landhäußer \& Keller, 2012). Engeser and Rheinberg (2008) found that the flow experience led to improved performance in participants who played the game Pac-Man at three difficulty levels, while Jin (2012) reported that successful performance resulted in a greater flow experience in participants who played the games Call of Duty: World at War and Trauma Center: New Blood. Therapeutic settings might also benefit from experimental flow research utilizing video games. The flow state is an experiential feature of altered states of consciousness which can lead to a diminished sense of self and time (Wittmann 2015, 2018). Distortions in the notions of the self and time have been reported in many patient groups with psychiatric disorders (Khoshnoud, Shamsi, Nazari, \& Makeig, 2017; Vogel et al., 2019; Vogel, Krämer, Schoofs, Kupke, \& Vogeley, 2018). The sense of self and time is overly represented in individuals with anxiety and depression, who are stuck with themselves in time and experience states that are the complete opposite of flow (Liknaitzky, 2017). Video games specifically make time fly in a pleasant way, which is one of the main aspects of the flow experience (Bisson, Tobin, \& Grondin, 2012; Tobin, Bisson, \& Grondin, 2010). The induction of flow states has been shown to alter the sense of time (Sinnett, Jäger, Singer, \& Antonini Philippe, 2020). By measuring flow levels and the temporal-processing ability, Sinnett and colleagues identified that the higher the subjective flow experience of the sport or music performance, the better the participant performed in the post-performance timing task compared to the pre-performance timing task. Inducing flow states in these individuals could potentially lower symptoms of anxiety and depression. A study with the video game Boson $X$ reported that playing it for six weeks reduced self-rumination and enhanced cognitive capacities in individuals with depression (Kühn, Berna, Lüdtke, Gallinat, \& Moritz, 2018). Considering the beneficial nature of flow on psychiatric symptoms, creating a flow experience might provide a helpful remedy in clinical psychology ${ }^{1}$. Since flow is an enjoyable mental state, keeping the player in a flow state is considered to be one of the most important goals for game designers (Chen, 2006; Salen \& Zimmerman, 2003; Schell, 2008). To address this, game designers and researchers attempt to maintain the player's flow state through affect-based,

\footnotetext{
${ }^{1}$ This is the approach in the EU-funded project VIRTUALTIMES - Exploring and modifying the sense of time in virtual environments under the principal investigators Kai Vogeley (Cologne), Anne Giersch (Strasbourg), Marc Erich Latoschik, Jean-Luc Lugrin (Würzburg), Giulio Jacucci, Niklas Ravaja (Helsinki), Marc Wittmann (Freiburg) and Xavier Palomer, Xavier Oromi (Barcelona).
} 
136 dynamic difficulty-adjustment (DDA) techniques (Afergan et al., 2014; Liu, Agrawal, Sarkar, \& 137 Chen, 2009; Park, Sim, \& Lee, 2014).

138 To successfully examine research questions related to flow and performance, therapeutic use, or

139

140

141

142

143

144

145

146

147

148

149

150

151

152

153

154

155

156

157

158

159

160

161

162

163

164

165

166

167

168

169

170

171

172

173

174 gamer experience, the experimental paradigm must be accompanied by a valid measurement of the flow state. The concept of flow was initially investigated using the Experience Sampling Method (ESM) in naturalistic contexts (Csikszentmihalyi \& Csikszentmihalyi, 1992). This method involves contacting participants at random moments throughout the day and asking them questions about the nature and quality of their experience (Csikszentmihalyi \& Larson, 1983).

Later studies optimized the ESM and designed new questionnaires to evaluate the flow experience. Some of these are the Flow State Scale (FSS, Jackson \& Marsh, 1996) first designed in the context of sports, the Flow Short Scale (Flow-Kurzskala; FKS, Rheinberg \& Vollmeyer, 2003) developed for different fields of activity, the Flow Questionnaire (FQ, Sherry et al., 2006), and the flow subscale of the Game Experience Questionnaire (GEQ, IJsselsteijn, De Kort, Poels, Jurgelionis, \& Bellotti, 2007) designed for evaluation of the subjective gaming experience, the Virtual-Course Flow Measure (Shin, 2006) developed in the context of online learning, the Flow State Scale for Occupational Tasks (Yoshida et al., 2013), and the Work-Related Flow Inventory (WOLF, Bakker, 2008) specifically aimed at measuring the flow of employees. However, assessment of the flow experience with these retrospective questionnaires interrupts the ongoing activity and probably disrupts the flow experience. Utilizing these self-reported, post-task questionnaires cannot provide information about characteristics of this experience, like the mean duration or depth of flow. It is crucial to find non-disruptive, objective measures to continuously evaluate the flow experience. One way to assess this experience without interrupting it is to find neural and electrophysiological correlates of this state, which in turn could help to better understand the underlying physiological mechanisms. Apart from these internal correlates, another promising method would be the application of dual-task approaches that indirectly measure the extent to which subjects experience flow by assessing their levels of focused attention.

Here we provide an overview of all findings concerning the physiological and neural correlates of the flow experience. We believe this is the first review that combines both the physiological and neural correlates of flow in the context of video games. Harris et al. (2017) conducted a review on the neurocognitive mechanisms of flow with more emphasis on sports, as well as on the role of attention, suggesting attentional changes as the fundamental mechanism for the creation of the flow state. The role of physiological arousal was not discussed in detail in their review. Only peripheral-nervous-system indicators of flow were explored in a broad range of tasks identifying increased levels of arousal as a central approach to the physiological measurement of flow in a recent systematic review conducted by Knierim et al. (2018). We aimed to make a key contribution to the field of flow in the context of video games by considering reflections of flow in the central and peripheral nervous systems and integrating main physiological and neural mechanisms of the flow experience. Based on the results of the 
175 reviewed studies, we suggest possible explanations for the heterogeneity of the findings and how 176 to distinguish the internal phenomenon of flow from the external characteristics of the task. For 177 the sake of consistency, given that different studies label conditions in different ways, in the 178 following we will refer to difficult conditions as "over-challenged", to easy ones as "underchallenged", and to optimally challenged conditions as "flow."

180

181

182

183

184

185

186

187

188

189

190

191

192

193

194

195

196

197

198

199

200

201

202

203

204

205

206

207

208

209

210

211

\section{Survey methodology}

We identified relevant academic articles in the Web of Science and PubMed databases using the search terms: [(flow OR absorption) AND (physiological OR electrophysiological OR neurophysiology OR brain activity OR neural activity) AND (game OR video game OR gameplay)]. This search provided a total of 215 citations. After removing duplicates, the set of 55 articles comprising peer reviewed, empirical studies focused on the physiological and neural phenomenon of the flow experience while playing video games without a-priori, publication-date restrictions was selected. Another 18 studies were identified by scanning the references listed in the literature found in the initial search. Thirty-five articles, including research on exergames (videogames in the form of exercise) and multiplayer games, were further excluded by applying the inclusion criteria to the full texts of the manuscripts, as they introduced other confounding factors (e.g., movement effects and social interaction). The 38 articles included in the review are presented in two sections: peripheral-physiological and neural correlates of flow.

\section{Peripheral-physiological correlates of flow}

Before introducing the empirical work, it is necessary to discuss the theoretical background of the peripheral-physiological correlates of flow. During the flow state, feelings of enjoyment along with high levels of concentration and focused attention are indicative of the involvement of the emotional and attentional systems of the brain. Based on this line of thought, several hypotheses have been proposed, which we will discuss in the following sections. First, the experimental approach by Kivikangas (2006) defined the flow experience as a state of positive valence and heightened arousal. Later, de Manzano and colleagues described the physiology of flow as a combination of positive valence, heightened arousal, and effortless attention that arises through the interaction between positive affect and focused attention (de Manzano, Theorell, Harmat, \& Ullén, 2010; Ullén, de Manzano, Theorell, \& Harmat, 2010). According to this hypothesis, flow is associated with parasympathetic modulation of the sympathetic branch of the autonomic nervous system (ANS). Ullén et al. (2010) argued that this co-activation of the sympathetic nervous system (SNS) and the parasympathetic nervous system (PNS) acts as a physiological coping mechanism for high demands of attention and can distinguish between states of effortful and effortless attention. In contrast to the notion of effortless attention, which is typical of the flow experience, Keller and colleagues (2011) argued that flow involves considerable mental effort due to a high degree of involvement along with the challenging nature of the task. 
212 Finally, by combining the stress-model with the flow-model, Peifer et al. (2014) proposed that

213 the experience of challenge during flow induces a certain amount of stress accompanied by

214 heightened physiological arousal, as indicated by increased activation of the SNS (fast response

215 system) and the hypothalamic-pituitary-adrenal (HPA) axis (slow response system). They

216 suggested an inverted U-shaped relationship between flow experience and physiological arousal

217 with a moderate arousal level during flow and lower and higher levels of arousal for the under-

218 challenged and over-challenged conditions, respectively. Reported negative effects of exogenous

219 cortisol dosage on experienced flow supports their recent proposition of an inverted U-shaped

220 relationship between cortisol and flow (Peifer, Schächinger, Engeser, \& Antoni, 2015).

221 Empirical studies in this field (see Table 1) are presented in the following section. However,

222 inconsistent results during flow states show that the relationship among the flow experience,

223 arousal, and mental effort is highly dependent on the task.

224

225

226

227

228

229

230

231

232

233

234

235

236

237

238

239

240

241

242

243

244

245

246

247

248

249

** INSERT TABLE 1 HERE **

\section{Positive valence and heightened physiological arousal}

One of the first studies that investigated correlations among valence, arousal, and flow was conducted by Kivikangas (2006). The study assessed the participants' facial electromyographic (EMG) activity as an index of emotional valence (Lang, Greenwald, Bradley, \& Hamm, 1993; Larsen, Berntson, Poehlmann, Ito, \& Cacioppo, 2008) and electrodermal activity (EDA) as a sensitive measure of arousal (Boucsein, 2012) while they played the science-fiction computer game Halo: Combat Evolved. The activity of the corrugator supercilii muscle (CS, "frowning muscle"), an index of negative valence, was negatively associated with the flow scores assessed by the FSS questionnaire, showing decreased negative valence during the experience of flow. No significant effect was found for zygomaticus-major (ZM, "smiling muscle") or for orbicularis oculi-muscle (OO, "eyelid muscle") activities - indices of positive valence - or for EDA activity. Chanel et al. (2008) employed physiological measures, including cardiovascular activity and EDA, to determine the three emotional states induced by under-challenged, flow, and overchallenged conditions of the game Tetris by modulating the difficulty of the game.

Cardiovascular activity is reflective of ANS activity, with heart rate (HR) being stimulated by the SNS and inhibited by the PNS activity (Shaffer \& Ginsberg, 2017). The behavioral results demonstrated that participants felt the highest positive valence and had a medium arousal level in the flow condition in contrast to the under-challenged and the over-challenged conditions.

Electrophysiological measures showed heightened arousal levels as the difficulty of the game increased, which was identified by an increase in EDA and the HR (increased SNS activity). Utilizing a modified version of the first-person-shooter (FPS) game Half-Life 2 with specificallydesigned levels, Nacke and Lindley (2008) assessed immersion along with under-challenged and flow states by correlating these states with the objective electrophysiological measures. The significantly highest mean ZM muscle activity and EDA values were detected during the flow game level. However, the flow experience was not evaluated by any questionnaire, and it is not 
250

251

252

253

254

255

256

257

258

259

260

261

262

263

264

265

266

267

268

269

270

271

272

273

274

275

276

277

278

279

280

281

282

283

284

285

286

287

clear whether participants experienced flow in the flow condition of the game. In a correlational study employing three FPS games, no significant correlation was reported between EDA activity and flow scores assessed by the flow dimension of the GEQ, while the HR was reported to negatively correlate with flow (Drachen et al., 2010).

Bian et al. (2016) presented a physiological evaluation model for the state of flow in the virtualreality (VR) game Air Bombardment. In contrast to the findings of the study by Nacke and Lindley, (2008), the authors reported no correlations between ZM activity and flow scores as assessed by the FKS questionnaire. Using a mental-arithmetic task, a study by Ulrich and colleagues found an inverse U-shaped pattern for EDA with significantly higher values during the flow condition than during the under-challenged and over-challenged conditions, highlighting higher arousal levels during the experience of flow (Ulrich, Keller, \& Grön, 2016). EDA was also assessed while playing the Blocmania $3 D$ game with three levels of difficulty corresponding to under-challenged, flow, and over-challenged states (Tian et al., 2017). Difficulty manipulation was assessed with the FSS questionnaire. The highest flow state which was reported during the flow condition of the game was associated with moderate EDA activity, which reflects moderate sympathetic arousal. In a single-case study, Moreno et al. (2020) reported that a flow-like state in an expert gamer while playing the puzzle game Portal coincided with increased EDA. In their study, physiological assessment was not conducted during the moments of flow, but when individuals were goal-oriented during gameplay.

\section{Co-activation of the sympathetic and the parasympathetic nervous systems}

Findings regarding the relationship between the flow state and ANS are mixed, as both sympathetic and parasympathetic activity have been shown to correlate with flow in combination and alone. De Manzano et al. (2010) argued that the flow state experienced while playing piano is linked to increased parasympathetic modulation of sympathetic activity. Their study showed that the flow reports of the pianists (as assessed by the FSS questionnaire) correlated with a decreased heart period (HP, increased SNS activity), decreased heart rate variability (HRV, fluctuations in the time intervals between heartbeats and an index of parasympathetic activity) (Laborde, Mosley, \& Thayer, 2017), an increased LF/HF ratio (low frequency HRV/high frequency HRV, reflecting autonomic balance between the SNS and the PNS), and increased respiratory depth (RD, increased PNS activity) (de Manzano et al., 2010). Chanel et al. (2011), in contrast, reported less low-frequency heart-rate variability (LF-HRV) during flow compared to under-challenged and over-challenged conditions while playing Tetris. In a computerized knowledge task, Keller et al. (2011) reported lower HRV during the flow condition compared to under-challenged and over-challenged conditions, indicating less parasympathetic activity. A more detailed assessment of cardiovascular and respiratory responses was performed by Harmat et al. (2015) during trials of Tetris gameplay in all three conditions: under-challenged, flow, and over-challenged. The flow condition was characterized by the highest levels of flow measured by the FSS questionnaire. More flow was associated with greater respiratory depth (reflecting 
288

289

290

291

292

293

294

295

296

297

298

299

300

301

302

303

304

305

306

307

308

309

310

311

312

313

314

315

316

317

318

319

320

321

322

323

324

325

increased parasympathetic activity) and lower LF-HRV (reflecting both sympathetic and parasympathetic influences). Given the lack of a significant relation between HF-HRV (highfrequency HRV, a direct measure of parasympathetic activation) and flow, their results did not clearly support the hypothesis that the flow state is linked to activation of the sympathetic and the parasympathetic nervous systems (Harmat et al., 2015). Tian and colleagues (2017) also reported moderate HR and HRV along with increased RD during the flow condition while playing the game, suggesting increased parasympathetic modulation of sympathetic activity during the flow experience. In a FPS game called Unreal Tournament 2004, lower HF-HRV was reported in subjects playing the game during the flow condition compared to under-challenged and over-challenged conditions (Kozhevnikov, Li, Wong, Obana, \& Amihai, 2018). Given the lack of a significant change in the LF-HRV values, the authors argued that this pattern of reduction in parasympathetic activity is critical for achieving flow. The flow experience was not assessed directly in their investigation, and it is not clear whether subjects subjectively experienced higher flow while playing the game during the flow condition as compared to the other two conditions.

Both the HRV and the HF-HRV are considered as sensitive indices of parasympathetic activity (Laborde et al., 2017; Malik et al., 1996; Shaffer \& Ginsberg, 2017), which was reported to be causally involved in flow experience (Colzato, Wolters, \& Peifer, 2018). The interpretation of LF-HRV is controversial, since it is considered a marker of sympathetic modulation (Kamath MV, 1993) and both sympathetic and vagal influences (Laborde et al., 2017; Malik et al., 1996; Shaffer \& Ginsberg, 2017). A comprehensive literature review conducted by Reyes del Paso et al. (2013) challenged this interpretation that the LF and LF/HF ratios reflect sympathetic activity and autonomic balance, respectively, and suggested that the LF component of the HRV is mainly determined by the parasympathetic system.

\section{Effortless or effortful attention}

According to Ullén et al. (2010), the co-activation of the SNS and the PNS results from the interaction between positive affect and high attention, which leads to a state of effortless attention. The flow experience is characterized by heightened concentration and heightened attention. Specific patterns of activity, like an increased heart rate, decreased HRV, shallow respiration, and increased facial EMG activity, are signs of mental effort (Aasman, Mulder, \& Mulder, 1987; Backs \& Seljos, 1994; Veltman \& Gaillard, 1998; Waterink \& van Boxtel, 1994), which are distinctive from the observed results in studies concerned with flow. In contrast to the idea of effortless attention, Keller et al. (2011) linked reduced HRV to increased mental effort during the experience of flow in a computerized knowledge task. During simulation-based training on the use of the enterprise resource planning software with the three levels of difficulty (under-challenged, flow, and over-challenged), Léger et al. (2014) reported less mental effort during flow. According to their results, participants who exhibited smaller variations in their EDA levels (i.e. being more emotionally stable), lower HR, and higher HRV (indicative of less 
326

327

328

329

330

331

332

333

334

335

336

337

338

339

340

341

342

343

344

345

346

347

348

349

350

351

352

353

354

355

356

357

358

359

360

361

362

363

mental effort) were reported to be more likely to be cognitively absorbed. Peifer et al. (2014) also reported a positive linear relationship between HRV values (HF-HRV) and flow in a computer task (Cabin Air Management System Simulation). The participants's stress levels were manipulated via the Trier Social Stress Test (TSST) before they performed the task. After the task, their flow experience was evaluated with the FKS questionnaire. Flow was associated with increased HF-HRV, reflecting a decrease in mental effort. These results contradicted the findings by Keller and colleagues (Keller et al., 2011), who found a negative relationship between flow and parasympathetic activity. The different findings indicate that during a difficult level of a computerized knowledge task or game, participants may not perceive as much stress and threat as they might experience during the TSST, which is designed to create considerable social anxiety. Keller's study involved a relatively small number of participants and operationalized flow through skill-challenge balance in the flow condition, without actually measuring selfreported flow experiences, which might affect the validity of their findings.

Harris et al. (2016) explored whether concentration during flow is related to objective indices of effortful attention processing in a simulated car-racing task with the three standard levels of difficulty (under-challenged, flow, and over-challenged). The FKS questionnaire was used to check for experimental manipulation. The authors reported significantly higher flow scores for the flow condition during the game. The observed higher mental effort (lower HRV) and more focused attention (more focused eye gaze) along with less self-reported subjective effort in the flow condition than in the over-challenged condition suggested that the experience of flow is based on an efficient, but effortful, engagement of attention. The link between attention and flow was also examined by De Sampaio Barros et al. (2018) to see whether flow mobilizes attentional resources while playing two video games, Tetris and Pong. The authors added an "autonomy" condition to the traditional under-challenged, flow, and over-challenged conditions. They argued that this opportunity to determine the difficulty level oneself is an important factor for experiencing flow. However, the flow scores measured by the FKS questionnaire in the flow (pre-selected) and autonomy (self-selected) conditions were similar, albeit greater than in the under-challenged and over-challenged conditions. The HR significantly increased with task difficulty, and the HRV was lower during the autonomy level than during the other conditions for both games, suggesting higher mental effort during autonomy.

\section{The inverted U-shaped relationship between flow and the stress system}

A number of studies on the physiology of flow found associations between flow and physiological activation of the stress system. Keller and colleagues (2011) reported that a state of flow while playing a game involves high levels of tension reflected by higher salivary cortisol levels (increased HPA-axis activation). In the second experiment, the authors utilized Tetris in the three aforementioned conditions to see whether high involvement during the flow experience was associated with increased salivary cortisol levels. Higher cortisol levels were reported for the flow and over-challenged conditions. By combining the stress model with the flow model, Peifer 
364

365

366

367

368

369

370

371

372

373

374

375

376

377

378

379

380

381

382

383

384

385

386

387

388

389

390

391

392

393

394

395

396

397

398

399

400

401

et al. (2014) suggested an inverted U-shaped curve between LF-HRV and cortisol level on one hand and the flow experience assessed by the FKS questionnaire on the other hand, revealing moderate LF-HRV and cortisol levels in flow and low and high LF-HRV and cortisol values during under-challenged and over-challenged conditions, respectively.

The functional association between HRV factors (LF-HRV and HF-HRV) and flow (measured by the FKS questionnaire) was also assessed during a driving-simulation game (Tozman, Magdas, MacDougall, \& Vollmeyer, 2015). The task used was a driving simulator chosen from the sporting-race, video-game package Rfactor with the three fixed levels of difficulty. An increase in task difficulty caused a decrease in the HF-HRV and LF-HRV components. In contrast to the findings by Peifer et al. (2014), which showed an inverted U-shaped relation between flow and HRV measures, there was a negative linear connection between LF-HRV and flow when the conditions for flow were met (flow condition) and an inverted U-shaped relation between LF-HRV and HF-HRV, on the one hand, and flow, on the other hand, when demands exceeded the skill level (over-challenged condition) (Tozman et al., 2015). In a VR game, Bian et al. (2016) reported results similar to the previous studies showing that increased HR, HRV, and respiratory rate (RR), as well as shorter inter-beat intervals (IBI), predict an increase in the flow score as assessed by the FKS questionnaire. An inverted U-shaped function between LFHRV and HF-HRV and flow was also reported, highlighting moderate LF and HF-HRV levels for high flow scores and both low and high values of LF and HF-HRV for low-flow scores. The authors stated that the physiological aspects of flow in VR games may be particularly affected by the VR environment (Bian et al., 2016).

\section{Neural correlates of flow states}

There is still considerable conceptual ambiguity concerning the possible brain mechanisms involved in the flow experience. Here we are going to discuss the main hypotheses established in the literature. Given the effortlessness and automatic characteristics of flow, Dietrich (2004) argued that such an optimal performance state is controlled through an implicit rather than an explicit information-processing system in the brain. The explicit system, which is associated with higher-order cognitive functions, is rule based, can be verbalized, is connected to conscious awareness, and is supported by frontal-lobe activation. In contrast, the implicit system is skill based, cannot be verbalized, is inaccessible to conscious awareness, and is supported primarily by the basal ganglia. Dietrich proposed that inhibition of the explicit system and transient hypofrontality is a necessary prerequisite for the experience of flow (Dietrich, 2004). The synchronization theory of flow proposed by Weber et al. (2009) specifies neuropsychological processes of the flow experience, considering that it is characterized by intense concentration and autotelic activity. This theory is based on Posner's tripartite theory of attention involving executive, alerting, and orienting networks (Posner, Inhoff, Friedrich, \& Cohen, 1987). Accordingly, the optimal and gratifying experience of flow results from synchronized activity in the attentional and reward networks under the balanced skill-challenge condition (Weber et al., 
402

403

404

405

406

407

408

409

410

411

412

413

414

415

416

417

418

419

420

421

422

423

424

425

426

427

428

429

430

431

432

433

434

435

436

437

438

2009). Csikszentmihalyi (1975) described the flow experience as "self-forgetfulness" or "loss of self-consciousness," highlighting the fact that, when the demands of the activity require the allocation of all attentional resources, attention is directed away from the self. Loss of selfawareness, as one of the important components of flow, sheds light on another interesting line of research that investigated the default mode network (DMN) activity during the flow experience (Sadlo, 2016). The activity of the DMN has been linked to self-referential thinking, and, therefore, declines in task-focused and goal-directed actions (Goldberg, Harel, \& Malach, 2006; Raichle et al., 2001). During moments of flow, DMN activity is thought to decrease, highlighting less self-referential processing (Peifer, 2012; Sadlo, 2016). Table 2 presents articles exploring brain activation during the flow experience.

\section{** INSERT TABLE 2 HERE **}

\section{Transient Hypofrontality}

The transient-hypofrontality hypothesis proposed by Dietrich (2004) was addressed by a few studies. Applying brain-imaging techniques in blocks of mental-arithmetic tasks with the aforementioned three levels of difficulty, Ulrich et al. $(2014,2016)$ reported a relative decrease in the activity of the medial prefrontal cortex (MPFC) in the flow condition. Other studies failed to confirm this finding. In a functional near-infrared spectroscopy (fNIRS) study, Yoshida et al. (2014) explored the activity of the prefrontal cortex (PFC) during flow and under-challenged levels of playing Tetris and failed to verify the transient hypofrontality hypothesis. Flow scores assessed with the Flow State Scale for Occupational Tasks (Yoshida et al., 2013) were higher in the flow than in the under-challenged condition. Significantly higher activation of the left and right ventrolateral prefrontal cortex (VLPFC) was reported during the final 30 seconds of flow than throughout the entire flow condition; the same trend was not observed during the underchallenged condition (Yoshida et al., 2014). Harmat et al. (2015) also failed to show an association between decreased activity in frontal-brain regions and flow while playing Tetris. None of their fNIRS analyses revealed associations between lower frontal-cortical activation and flow, suggesting that the neural substrates of flow may vary depending on the task (Harmat et al., 2015). De Sampaio Barros et al. (2018) recorded the cerebral hemodynamics of 20 volunteers while they played Tetris and Pong. The flow and autonomy playing conditions not only led to higher activation in the lateral PFC, but also to higher deactivation in the MPFC compared to the other conditions.

It seems that the neural signature of transient hypofrontality during flow is task dependent. In tasks which require sustained attention, a deactivation of prefrontal areas seems unlikely. Gold \& Ciorciari (2019) investigated whether decreased excitability over the left dorsolateral prefrontal cortex (DLPFC) and increased excitability in the right parietal cortex during gameplay promotes an increased experience of flow as measured by the FSS questionnaire. Transcranial, directcurrent stimulation (tDCS), which is a non-invasive, electrical-stimulation technique that 
439

440

441

442

443

444

445

446

447

448

449

450

451

452

453

454

455

456

457

458

459

460

461

462

463

464

465

466

467

468

469

470

471

472

473

474

475

476

modulates the activation of the cortical neurons under a probe electrode, was used to alter the excitability of the cortex. In the first experiment, they recruited trained gamers to play one of two FPS video games (Counter Strike: Global Offensive or Battlefield 4) in two sessions using active and sham tDCS stimulation. The second experiment was conducted with untrained gamers playing Tetris in under-challenged, flow, and over-challenged conditions. Both trained FPS and untrained Tetris players experienced significantly higher levels of flow after the active stimulation compared to the sham condition. The authors argued that inhibiting the DLPFC and the disruption of explicit executive functions resulted in improved implicit information processing and a more intense flow experience (Gold \& Ciorciari, 2019).

\section{Synchronization of attentional and reward networks}

One of the first studies to assess the neural correlates of enjoyment while playing video games by means of functional-magnetic-resonance imaging (fMRI) was conducted by Klasen and colleagues in 2008. The participants' brain activation was measured in relation to their subjective experience, which was assessed by having participants think aloud while they watched a replay of their gameplay session with an FPS game (Counter-Strike: Source). Reported game pleasure was correlated with cerebro-thalamic motor-network and visual-network activity (Klasen, Zvyagintsev, Weber, Mathiak, \& Mathiak, 2008). In a subsequent study, Klasen et al. (2012) focused on game events that contribute to the flow factors described by Csikszentmihalyi, and corresponding fMRI data were analyzed while participants played an FPS video game called Tactical Ops: Assault on Terror. Somatosensory networks and motor areas were jointly activated during flow-contributing events (Klasen et al., 2012). The authors interpreted that this sensorimotor activation reflects the stimulation of physical activity, suggesting deep involvement and immersion in the game. The activation patterns of individual flow factors included the reward system (putamen, caudate nucleus, and thalamus), error monitoring (anterior cingulate cortex; ACC), the orbito-frontal cortex (OFC), temporal poles (TP), and the motor system. Specifically, reward-system activation was detected during game events with a skill-challenge balance, i.e. during moments when the player was able to master the challenges of the game and had a rewarding experience. The involvement of the reward system along with motor areas in both studies was considered in line with the synchronization theory of Weber et al. (2009). However, flow is a highly subjective phenomenon, and the second study did not examine the actual subjective flow experience, but events with an enhanced probability of flow.

Ulrich et al. (2016, 2014) also found increased activity in the inferior frontal gyrus (IFG, an executive attention structure) along with the left putamen (a region involved in reward processing), the anterior insula, and posterior cortical regions in the flow condition during the mental-arithmetic task. Yoshida et al. (2014) observed a higher activation of the right and left VLPFC during the flow condition while playing Tetris, which relates to reward and emotion processing in a state of flow. Considering the involvement of VLPFC in top-down attention (Raz \& Buhle, 2006), one can interpret this as a co-activation of the attentional and reward networks 
477 during the flow experience (Weber, Huskey, \& Craighead, 2016). The results of the study by De

478 Sampaio Barros et al. (2018) showed a significant positive correlation between the self-reported

479 measure of attention and the average neural activation in the frontoparietal regions. Higher

480 activation in the lateral PFC was reported in the flow and autonomy conditions while playing

481 Tetris and Pong compared to the other conditions. In a custom-designed car game, Ju and

482 Wallraven (2019) assessed the neural correlates of the flow experience with the flow subscale of 483 the GEQ. Besides a baseline driving condition with a fixed structure, they designed three extra

484 conditions to modulate the level of difficulty with one parameter (speed, obstacle, or tokens).

485 Although no significant differences in the flow-subscale ratings were reported across conditions,

486 the results of the fMRI analysis showed positive correlations between the flow scores and brain

487 activity in regions related to visual (dorsal and ventral visual pathways) and spatial execution

488 (middle and superior temporal gyri), as well as attentional processes (IFG, inferior and superior

489 parietal lobules).

\section{Self-referential processing}

491 Relating existing theories of the default mode network to the feeling of selflessness during flow,

492 Peifer (2012) argued that the down regulation of task-irrelevant processes during the experience

493 of flow should lead to decreased activity in these resting-state networks of the brain. First

494 empirical evidence came from a magnetic-resonance-based, perfusion-imaging study by Ulrich

495 et al. (2014), who found that a relative decrease in activity in the MPFC (an important structure

496 for self-referential processing) and the amygdala (AMY) accompany the experience of flow in a

497 mental-arithmetic task. The MPFC, the inferior parietal lobe, the posterior cingulate cortex

498 (PCC), and the precuneus constitute the DMN (Raichle et al., 2001). A flow index that was

499 specifically computed to represent the individually experienced level of flow correlated

500 negatively with activity in the MPFC (indicating less self-related processing) and the AMY. The

501 higher the subjective experience of flow, the greater the decrease in neural activity in the MPFC

502 and AMY. The authors later explored the neural effects of flow experience at higher levels of

503 temporal resolution using an fMRI block design with blocks of activation as short as 30 seconds

504 (Ulrich et al., 2016). This study yielded similar results as their previous study, with the addition

505 of decreased activation in the PCC, which altogether were interpreted as deep concentration and

506 less self-referential processing along with less emotional arousal (reflected by down-modulation

507 of AMY) during the flow experience. In the flow and autonomy playing conditions of the study

508 by De Sampaio Barros et al. (2018), decreased activity in the MPFC was also reported, which

509 highlighted less self-referential processing during the experience of flow. Ju and Wallraven

510 (2019) found negative correlations between the flow scores and brain activity in regions

511 associated with the DMN in a car-driving game. Authors argued that the DMN as a task-negative

512 network became more deactivated as players became more engaged in the game. Positive

513 correlations between flow and activity in the insula in this study also indicated less self-

514 awareness during moments of flow (Ju \& Wallraven, 2019). 
515 Ulrich and colleagues further explored the role of the MPFC in mediating flow experience using 516 tDCS stimulation to interfere with the level of MPFC activation by modulating cortical

517 excitability (Ulrich et al., 2018). During the above-mentioned mental-arithmetic task, current

518 stimulation was applied over the frontal-central (Fpz) scalp position with three types of

519 modulation: anodal (increase neuronal excitability), cathodal (decrease neuronal excitability),

520 and sham (baseline). Flow experience was assessed along with the implementation of MR-based

521 perfusion imaging while participants performed the task at three difficulty levels (under-

522 challenged, flow, and over-challenged). There was no significant difference among stimulation

523 types (sham, anodal, and cathodal tDCS) and the measured flow index across all subjects. After

524 splitting the subjects into two groups based on the flow index in the sham condition (lower flow

525 and higher flow), a significant increase in the flow index was reported in the lower-flow group

526 under anodal tDCS stimulation. Anodal tDCS elicited a significantly stronger deactivation of the

527

528 Neural oscillations and flow

529

530

531

532

533

534

535

536

537

538

539

540

541

542

543

544

545

546

547

548

549

550

551

Nacke \& Lindley (2010) proposed an affective ludology context referring to investigations of affective player-game interaction. To address this issue, some studies have explored how electroencephalogram (EEG, assessment of cortical activity of the brain through electrodes placed on the scalp) signals can differentiate emotions from cognitive activity during gameplay. Specific neural oscillations in four frequency EEG bands (delta, theta, alpha, and beta) were investigated as underlying neurophysiological mechanisms of the flow experience (see Table 3 ). These studies were mostly explorative without specific background theories. Some studies examined whether verbal-analytic processing is reduced during flow in accordance with the notion of peak performance and automaticity characteristics of the flow experience (specifically in athletes' motor responses) (Harris et al., 2017; Kramer, 2007; Wolf et al., 2015). Temporal alpha asymmetry has been shown to relate to peak performance, especially in athletes (Kerick, Douglass, \& Hatfield, 2004). According to Vernon (2005), higher left-temporal-cortex alpha activity, which reflects decreased cortical activity in this region, is associated with improved performance, as it represents a decrease in internal verbalizations and increased visual-spatial processing in the right hemisphere. Among frequency bands, frontal theta activity (specifically frontal mid-line theta) was of particular interest. Frontal mid-line theta has been linked to cognitive control and concentration (Brandmeyer, Delorme, \& Wahbeh, 2019; Cavanagh \& Frank, 2014) and may increase during the flow experience.

\section{** INSERT TABLE 3 HERE **}

Reduced verbal-analytic processing - Kramer (2007) studied neural correlates of peak performance (as associated with the state of flow) by exploring the power information of EEG signals in a car-driving game. A decrease in alpha power in the right-temporal lobe prior to a game trial predicted better game performance as reflected by an increase in visuo-spatial 
552 processing. Greater mean left-temporal alpha power ten seconds before a game trial resulted in

553

554

555

556

557

558

559

560

561

562

563

564

565

566

567

568

569

570

571

572

573

574

575

576

577

578

579

580

581

582

583

584

585

586

587

588

589

improved performance. Once again, the players' subjective flow experience was not directly evaluated, but the high-performance intervals functioned as a proxy for the subjective states. Wolf et al. (2015) later linked states of highly-focused attention in athletes (one key component of the flow experience) to a reduced influence of verbal-analytical processes reflected by stronger relative left-temporal-cortex alpha power. In this study, 35 expert and amateur tabletennis players were asked to watch a 7-second video clip of a table-tennis player serving a ball and to imagine themselves reacting to it. A significant change towards lower T4-T3 alpha power (stronger right-temporal-cortical activity) at the beginning of the movement phase was reported in experts. This result, along with a positive correlation between T4-T3 alpha asymmetry and the flow score (measured by the FKS questionnaire) in the experts, was interpreted to reflect lower verbal analytic processing as associated with a higher degree of flow in expert table-tennis players.

Delta and Theta frequency bands - Chanel et al. (2011) tried to classify the three states (underchallenged, flow, and over-challenged) induced by playing Tetris at three different challengeskill levels. Although their EEG results indicated distinct theta power among conditions in some electrodes, no precise relationship to the individual states (under-challenge, flow, and overchallenge) was found. Nacke and colleagues probed the impact of different difficulty levels of a game on brainwave activity in an exploratory EEG study (Nacke et al., 2011). The authors did not employ the difficulty modulation to create different levels of gameplay. Three gameplay conditions (under-challenged, immersion, and flow) of the game Half-Life 2 were created based on specific level-design guidelines (LDGs). Theta and delta power were significantly higher in immersion than in flow and the under-challenged condition. Since the immersion condition of the game required navigating through landmarks, the authors argued that high theta activity in this level might be attributed to its architectural complexity. In another study, EEG correlates of the flow state induced by playing a ping-pong video game were investigated at two levels, slow as boring and fast as flow inducing (Metin et al., 2017). EEG-frequency power evaluations revealed higher mean theta power during the flow condition for all regions of interest and higher mean delta power in frontal, central, and parietal regions compared to the non-flow condition. The regional theta- and delta-frequency bands correlated positively with the absorption, enjoyment, and intrinsic-motivation subscales of the Turkish version of the FKS flow questionnaire. Regarding the two playing levels, a higher theta band was to be expected in the more difficult (flow) condition, as theta activity has been linked to concentration, working memory, and sustained attention, which increase with higher difficulty levels. Katahira et al. (2018) characterized the flow state by increased theta activity in the frontal areas. Employing a mental-arithmetic task used in the previous study (Ulrich et al., 2014) with three levels of difficulty, theta activity in the frontal areas was reported to be higher during the flow and the over-challenged conditions of the task compared to the under-challenged condition.

Peer) reviewing PDF | (2020:05:49318:3:0:NEW 11 Nov 2020) 
590 Alpha frequency band - Alpha-power attenuation in the flow condition was seen as an indicator 591 that the subject had entered into a flow state (Berta, Bellotti, De Gloria, Pranantha, \& Schatten, 592 2013). Using a four-electrode EEG (F7, F8, T5, and T6), distinct states induced by a specifically 593 designed plane-battle video game were analyzed with appropriate levels for the under594 challenged, flow, and over-challenged conditions. The main differences among the three 595 conditions were reported in alpha and low-beta frequency-band powers with the lowest alpha and 596 low-beta in the flow state. There was no information regarding the region of observed distinct 597 frequency powers among conditions. Self-assessed flow scores of the GEQ revealed significant 598 differences at under-challenged and over-challenged levels, but failed to distinguish the flow 599 level. Léger et al. (2014) explored the relationship between EEG and flow in a simulation-based

600

601

602

603

604

605

606

607

608

609

610

611

612

613

614

615

616

617

618

619

620

621

622

623

\section{4}

625

626

627 training session at the three levels of difficulty. Subjects with high-alpha and low-beta activity reported higher cognitive-absorption scores. The authors argued that these results demonstrated a more relaxed and less vigilant state in the learners.

Beta frequency band - Wang \& Hsu (2014) explored the state of flow during a computer-based instruction paradigm utilizing EEG to see whether the attention score captured by the EEG signal was associated with the flow score assessed by the virtual-course flow measure. Participants completed three lessons on computer-based Excel instructions with under-challenged, flow, and over-challenged contents. The EEG attention value derived from the beta-wave-brain activity at the Fp1 electrode correlated with the flow dimensions of enjoyment, focused attention, involvement, and time distortion. However, the correlation coefficient was small, and the authors argued that the attention value did not precisely represent the flow experience and comprised only one component. Léger et al. (2014) found low-beta activity associated with a higher flow score, highlighting a less vigilant state in the learners. Utilizing an adapted version of the WOLF questionnaire, De Kock (2014) evaluated the flow experience of participants playing a continuous visuomotor computer game (Need for Speed Carbon). EEG-signal activity at prefrontal, sensorimotor, parietal, and occipital regions was compared between low-flow-/lowperformance and high-flow-/high-performance groups. The high-flow condition was associated with increased low-beta power in the sensorimotor cortex, as well as low-beta synchronization among all cortical connections. The shift in low-beta power in the sensorimotor area was connected to fluent and coordinated motion. Synchronized low-beta connections in all cortical regions in the high-flow condition indicated optimized transmission of neural information throughout the brain, ensuring smooth, accurate, and effortless motor execution (De Kock, 2014). Increased beta activity during flow-like states was also reported in a single-case study by Moreno et al. (2020) highlighting higher cognitive engagement during moments of flow.

\section{Implementation of dual-task paradigms}

Although the above-mentioned studies have provided neural signatures of the flow state, they all face a similar limitation. Their methodology cannot discern between internal flow and the external task conditions that facilitate the experience of flow. A skill-challenge balance is 
628 considered a prerequisite to inducing flow, but it does not guarantee that an individual will enter

629

630

631

632

633

634

635

636

637

638

639

640

641

642

643

644

645

646

647

648

649

650

651

652

653

654

655

656

657

658

659

660

661

662

663

664

665

666

the flow state. It has been demonstrated that different factors, but especially the methodology, can affect the association between skill-challenge balance and flow (Fong et al., 2015). In some studies in which difficulty modulation was used for creating under-challenged, flow, and overchallenged conditions, the adaptive playing condition was considered as flow inducing without any post-manipulation check to see whether participants really experienced flow in their experimental set-up (e.g., Chanel et al., 2011). This fact led to the application of techniques that indirectly measure the extent to which subjects experience flow by assessing their levels of attentional focus. Based on the flow theory (Csikszentmihalyi \& Csikszentmihalyi, 1992), focused attention during the experience of flow leads to complete absorption in an activity to the extent that one does not allocate attentional resources to irrelevant external stimuli. During under-challenged or over-challenged states, attentional disengagement from the task makes it more likely that an individual will pay attention to irrelevant stimuli. These considerations led to an interesting line of research using dual-task paradigms to indirectly measure electrophysiological correlates of the flow experience (see Table 4). Secondary-task reaction times were suggested as reliable and valid measures of available attentional resources (Weber, Alicea, Huskey, \& Mathiak, 2018).

\section{** INSERT TABLE 4 HERE **}

Castellar and colleageus utilized an auditory oddball paradigm as a secondary task to investigate attention while subjects played a game as a primary task (Castellar et al., 2016). Participants were requested to play the game Star Reaction in under-challenged, flow, and over-challenged conditions while simultaneously responding to a rare sound in the auditory oddball task. The greater the absorption in the primary task, the slower the reaction times and more errors registered in the detection of oddball sounds. Event-related-potential (ERP) analysis showed that the maximal frontocentral negative deflection after the response onset was significantly delayed during the flow condition compared to the other two conditions in the correct-responses trials, reflecting delayed attention reallocation to the primary task during flow. Significant increases in the midfrontal alpha power during the flow condition may well indicate the intrinsic rewarding nature of the flow experience (Castellar et al., 2016). A study by Yun et al. (2017) extended the secondary-task idea by adding a passive random beeping sound while subjects played an FPS game (Call of Duty: Modern Warfare 2). Complete absorption in the game world was expected to lead to the neglect of the game-irrelevant sensory stimulation from the real world, which is reflected by the suppression of auditory evoked potentials (AEPs) of EEG signals elicited by random beeps. Due to the insufficient number of trials and background noise, typically detected AEPs were not observable, and the authors instead analyzed event-related spectral-perturbation (ERSP) suppression at low frequencies in the flow trials. A significant correlation was reported between the suppressed evoked potentials derived from ERSP and the self-reported experience of flow. By utilizing source-localization algorithms, the activation of the ACC and the temporal pole was reported during flow trials only in the beta-frequency range. Subjective flow ratings

Peer) reviewing PDF | (2020:05:49318:3:0:NEW 11 Nov 2020) 
667 also positively correlated with activation in these regions, suggesting a link between the flow 668 experience and high concentration, focused attention, and less self-referential processing (Yun et 669 al., 2017).

670 Auditory oddball sounds were also applied as a secondary task in a VR gaming context to 671 explore attentional allocation during the experience of flow (Bombeke, Dongen, Durnez, \& 672 Anzolin, 2018). Participants played the shooter game Counter-Strike: Global Offensive under 673 three conditions (under-challenged, flow, and over-challenged) both in a 2D and a VR set-up 674 while they were simultaneously asked to respond to the oddball sounds. Their results did not 675 replicate the outcome of the previous study by Castellar et al. (2016), as they reported slower 676 reaction times and more errors in the flow condition. A marginally significant posterior mid-line 677 P300 amplitude was recorded during VR compared to playing in 2D during the flow condition.

678 The flow ratings measured with the FQ scale did not show any significant differences among the 679 different gaming conditions, and it is unclear whether participants really experienced under680 challenge, flow, and over-challenge in this set-up. Huskey et al. (2018) recorded the greatest

681

682

683

684

685

686

687

688

689

690

691

692

693

694

695

696

697

698

699

700

701

702

703 intrinsic reward (measured by the Autotelic Experience Subscale of the FSS questionnaire) and longer reaction times during the flow condition by applying a secondary-task reaction-time (STRT) procedure while subjects played the game Asteroid Impact at the three levels of difficulty. The flow condition elicited significantly greater activity in the areas related to cognitive control (DLPFC), orienting attention (superior parietal lobe; SPL), attentional alerting (dorsal anterior insula, dAI), and reward networks (putamen). In line with the synchronization theory of flow, the low-difficulty condition evoked activity in DMN structures which was absent in the high-difficulty condition (Huskey et al., 2018).

\section{Discussion}

We conducted a comprehensive review of the current literature on the underlying electrophysiological and neural mechanisms of the experience of flow. Although a number of physiological and neural measures could potentially be considered as markers of flow, it is difficult to relate them to a unified mechanism underlying this mental state. Flow is a complex state that requires the involvement of distinct cognitive subfunctions, which in turn necessitates the activation of different physiological and neural systems. Here we categorized some of these distinct physiological and cognitive subfunctions which were addressed by most of the studies.

\section{The state of positive valence and heightened arousal}

Activity in the smiling (ZM, positive association) and frowning facial muscles (CS, negative association) and greater respiratory depth during flow states represent positive affect (de Manzano et al., 2010; Harmat et al., 2015; Kivikangas, 2006; Mauri, Cipresso, Balgera, Villamira, \& Riva, 2011; Nacke \& Lindley, 2008). The pattern of arousal modulation, however, is complex and varies according to how studies used it to distinguish flow states from taxing experiences, such as stress. Peifer and colleagues (2014) proposed an inverted U-shaped function 
704 between the flow experience and physiological arousal. If we consider the relationship between

705 flow and performance (Csikszentmihalyi et al., 2005; Engeser \& Rheinberg, 2008; Jin, 2012;

706 Keller \& Bless, 2008; Landhäußer \& Keller, 2012), this pattern aligns well with the Yerkes-

707 Dodson Law, which proposes an inverted U-shaped association between arousal and

708 performance (Yerkes \& Dodson, 1908). Nevertheless, findings concerning the sympathetic and

709 parasympathetic reflections of arousal are heterogeneous, given that both linear (Chanel et al.,

710 2011; de Manzano et al., 2010; De Sampaio Barros et al., 2018; Keller et al., 2011; Tian et al.,

711 2017) and inverted U-shaped (Bian et al., 2016; Peifer et al., 2014; Tozman et al., 2015)

712 associations have been reported. On the other hand, EDA — a robust indicator of sympathetic

713 arousal (Critchley \& Nagai, 2013) - has been shown to positively correlate with flow, reflecting

714 heightened sympathetic arousal during moments of flow (Léger et al., 2014; Moreno et al., 2020;

715 Nacke \& Lindley, 2010; Ulrich et al., 2016).

716 One possible explanation of the linear function between arousal and the flow experience is that

717 playing a game in a laboratory setting, even at a higher level of difficulty, might not be perceived

718 as a threat and thus fails to elicit high levels of arousal at high levels of difficulty. Based on the

719 biopsychosocial model of challenge and threat, Tozman and Peifer (2016) suggested using

720 framing techniques to manipulate challenge appraisal in a game and create a threatening situation

721 during gameplay. The question is how a framing context affects flow experience, given that

722 external impositions, such as threat, negative feedback, and an imposed deadline, might

723 negatively influence intrinsic motivation and, consequently, the flow experience (Di Domenico

724 \& Ryan, 2017). Studies investigating the relationship between flow and salivary cortisol levels

725 (Keller et al., 2011; Peifer et al., 2015, 2014) also suggest that this relationship is moderated by

726 the type of intervention, personal characteristics, and the interaction of both (Brom et al., 2014).

727 It is also possible that the internal motivation for gameplay was adversely affected by the

728 experimental setup, as players participated in the experiment not for the pleasure of the game,

729 but for the specific context. Being in an artificial experimental situation and receiving external

730 rewards (e.g., monetary compensation) may suppress arousal. It is worth mentioning that the LF-

731 HRV which was considered a marker of sympathetic activity in the study by Peifer and

732 colleagues (2014), was determined mainly by activity in the parasympathetic system (Reyes del

733 Paso et al., 2013). Future studies should consider more robust indicators of sympathetic arousal

734 to evaluate the relationship between flow and physiological arousal. The pre-ejection period of

735 cardiovascular activity was suggested as a reliable indicator to clarify this inconsistency

736 (Tozman \& Peifer, 2016). Generally speaking, the simultaneous presence of heightened arousal

737 and positive valence can distinguish flow from the experiences of under-challenged and over-

738 challenged conditions.

739 The joyous state of focused attention

740 Flow as a state of complete concentration during a balanced skill-challenge condition

741 necessitates a high degree of attention that is understood to be effortless. Both flow and mental 
742 effort increase with increasing task difficulty (Tozman \& Peifer, 2016), but the specific pattern

743 of activity in the autonomic nervous system observed during the flow experience (e.g., decreased

744 heart period with deep respiration) is different from the pattern associated with mental effort

745 (e.g., decreased heart period, lower HRV, and rapid and shallow respiration). Studies that found

746 lower HRV in the flow condition explained this phenomenon in the light of greater mental effort

747 during the experience of flow (De Sampaio Barros et al., 2018; Harris et al., 2016; Keller et al.,

748 2011). In contrast, studies that observed a higher HRV suggested lower mental effort (Bian et al.,

749 2016; Peifer et al., 2014). The inconsistent findings regarding mental effort and flow experience

750 could be partly traced back to the imprecise measures used for assessing mental effort. Although

751 HRV has been found to be a sensitive indication of mental effort (Aasman et al., 1987; Backs \&

752 Seljos, 1994; Waterink \& van Boxtel, 1994), Veltman and Gaillard (1998) argued the opposite,

753 as it can be affected by respiratory activity. For instance, during moments with more rapid

754 respiration, differences in mental effort measured by HRV might be overestimated. It is,

755 therefore, necessary to test more precise measures of the suppression of the cardiovascular

756 control system resulting from mental effort. Blood glucose and pupil dilation were suggested as

757 sensitive measures to explore mental effort (Saproo, Shih, Jangraw, \& Sajda, 2016; Tozman \&

758 Peifer, 2016) which have not been investigated in the context of flow.

759 Harris et al. (2016) demonstrated that subjective and objective attentional effort might separate 760 from one other. Focused eye gaze (increased attention) and lower HRV (higher mental effort) 761 reported during the flow condition did not match the lower effort scores obtained through self-

762 report (Harris et al., 2016). Ullén et al. (2010) suggested that this may occur as a result of an 763 interaction between positive valence and focused attention. In a state of positive affect, a task

764 requiring considerable mental attention might be experienced as less effortful than when 765 accompanied by a state of negative affect. Observed co-activation of the sympathetic (reflected 766 by decreased HP) and parasympathetic systems (reflected by deep respiration) aligns well with 767 this suggestion. Considering the role of the PFC in attention and concentration, the experience of 768 flow was found to be associated with increased activity in this integrative frontal area of the 769 cortex (Klasen et al., 2012; Ulrich et al., 2016, 2014; Yoshida et al., 2014). Frontal-midline-theta 770 activation has been linked to concentration, working memory, and sustained attention (Cavanagh 771 \& Frank, 2014). High theta activity reported during flow (Katahira et al., 2018; Metin et al., 772 2017; Nacke et al., 2011) may well reflect focused attention. We consider the flow state to be 773 accompanied by an efficient attentional effort and that the coupled activity of the sympathetic 774 and parasympathetic nervous systems can be used to distinguish this joyous state of focused 775 attention from a purely onerous mental experience.

\section{Synchronized activation of attentional and reward networks}

777 Flow is considered to be a state of focused attention which is intrinsically rewarding, as the flow778 inducing task is performed for its own sake. Some studies support the synchronization theory of 779 flow (Weber et al., 2009) by showing the joint activation of frontoparietal attention networks 
780 (e.g., IFG and inferior parietal lobe) and reward networks (e.g., putamen, thalamus) during the 781 flow experience (Castellar et al., 2016; De Sampaio Barros et al., 2018; Huskey et al., 2018; Ju 782 \& Wallraven, 2019; Klasen et al., 2012; Ulrich et al., 2016, 2014; Yoshida et al., 2014). A 783 positive correlation between dopaminergic receptor availability in the striatum and putamen and 784 flow proneness supports this theory and shows that the experience of flow is intrinsically 785 rewarding (de Manzano et al., 2013).

\section{Automaticity}

787 Inhibition of the explicit system and the transient hypofrontality theory (Dietrich, 2004) received 788 partial empirical support from studies on the neural mechanisms underlying the experience of 789 flow (Gold \& Ciorciari, 2019; Ulrich et al., 2016, 2014). Other studies failed to find transient 790 hypofrontality during the state of flow (Harmat et al., 2015; Yoshida et al., 2014). Fluent, 791 smooth, and effortless motor performance was related to increased low-beta power in the

792

793

794

795

796

797

798

799

800

801

802

803

804

805

806

807

808

809

810

811

812

813

814

815

816 sensorimotor cortex and low-beta synchronization among all cortical connections (De Kock 2014). This hypothesis might be an oversimplification of the flow state or only be related to specific situations. During tasks with high demands on executive control, a decoupling of actions from conscious effort and controlled attention is unlikely to happen. It has been suggested that the decrease in frontal functions is more likely to occur when the action becomes more automatic (Harris et al., 2017). This means that transient hypofrontality might happen after prolonged practice.

\section{Loss of self-awareness}

A promising consistent outcome of neural research on flow experience is the deactivation of the DMN, specifically the MPFC, which indicates less self-referential processing during the flow experience (De Sampaio Barros et al., 2018; Ju \& Wallraven, 2019; Sadlo, 2016; Ulrich et al., 2016, 2014, 2018). It has been stated that during the performance of cognitively demanding tasks, the activity of the central executive network and the salience network increases whereas DMN activity decreases (Sridharan, Levitin, \& Menon, 2008). Activity in the DMN is reported to be associated with a relaxed mind, mind-wandering, and self-referential thinking, which are reduced in task-focused and goal-directed actions (Goldberg, Harel, \& Malach, 2006; Raichle et al., 2001). Reduced activity was found in the DMN during focused sensory perception (Goldberg et al., 2006), which reflects the loss of self during the activity. Activation of DMN regions was also reported during a boredom-induction task, suggesting a relation between mind wandering and DMN activity (Danckert \& Merrifield, 2018). Several studies discussed the role of the MPFC and its relatively decreased activity in self-referential processing (Goldberg et al., 2006; Gusnard, Akbudak, Shulman, \& Raichle, 2001; Raichle et al., 2001). This is strongly related to Csikszentmihalyi's (1990) dimension of loss of self-awareness in flow theory. High concentration and focused attention demanded by the task at hand restrict resource allocation for task-irrelevant demands like body and self-awareness. Sridharan et al. (2008) stated that the 
817 salience network, including the VLPFC and the anterior insula (AI), is involved in shifts between 818 the DMN and cognitive executive networks acting as an outflow hub at the junction of both 819 networks. This theory is further confirmed by the positive correlation between the flow 820 experience and the increase in activity in the insular cortex, especially in the anterior insula 821 (Huskey et al., 2018; Ju \& Wallraven, 2019; Ulrich et al., 2016). Consequently, higher activity in 822 the anterior insula might show disengagement of the task-irrelevant DMN regions during the 823 experience of flow. Activity in anterior and posterior parts of the insula was linked to time 824 perception (Wittmann, Simmons, Aron, \& Paulus, 2010), and the anterior regions were shown to 825 associate with the experience of bodily self-awareness (Craig, 2009). A study by Berkovich826 Ohana et al. (2013) reported that timelessness during meditation is accompanied by higher theta

827

828

829

830

831

832

833

834

835

836

837

838

839

840

841

842

843

844

845

846

847

848

849

850

851

852

853

854

activation in the right insula. The role of the anterior insula in the experience of flow should be clarified by further investigations.

Another important issue here is that lower self-referential information processing is associated with decreased neural activity in the amygdala during flow (Ulrich et al., 2016, 2014, 2018). Given the amygdala's mediating role in the perception of emotions (Morris et al., 1996), reduced activity in AMY likely reflected decreased emotional arousal associated with the experience of flow. Lower self-awareness may reduce the threat response and increase positive emotions (Sadlo, 2016; Ulrich et al., 2016). Reduced awareness of the self is also reported to contribute to improved athletic performance (Harris et al., 2017). The close relationship between flow experiences and performance (Engeser \& Rheinberg, 2008; Jin, 2012; Landhäußer \& Keller, 2012) suggests that reduced self-awareness and DMN activity is one of the underlying key features of the flow experience.

\section{Task dependency}

Some of the inconsistencies in results can be explained by different experimental designs used in different research approaches. While some studies used continuous playing and correlational analysis, others preferred a difficulty-modulation approach in which they designed three game levels corresponding to the under-challenge, flow, and over-challenge categories of the flow model. The way the skill-challenge balance is operationalized in these studies directly influences flow. Studies frequently used global flow scales, like the FSS or the FKS questionnaires, to measure participants' levels of flow. A few studies merely applied some individual items or subscales of these surveys to assess the subjective experience (Keller et al., 2011; Ulrich et al., 2016, 2014), and some others did not employ any measure for the evaluation of flow and theorized that the skill-challenge-balance condition induces a flow state without further controlling for the effects of this manipulation (e.g., Chanel et al., 2011; Nacke \& Lindley, 2008; Nacke et al., 2011). In a meta-analysis, Fong et al. (2015) reported that the correlation between flow and optimal balance is higher when a global flow scale and one of its subscales of challenge-skill fit was used to operationalize a skill-challenge fit. The length of the experimental blocks, ranging from 30 seconds to 12 minutes, is another limitation which leads to strong 
855 variations in the strength of the flow experience. It has been stated that participants require a 856 minimum of 25 minutes to get into the flow state (Bisson et al., 2012; Tobin et al., 2010; Yun et

857 al., 2017). The next concern is that different paradigms or games require the involvement of 858 different cognitive functions, which in turn affect the outcomes of physiological and neural 859 activity. Peifer (2012) argued that, since the physiological and cognitive demands of the flow860 inducing activities are different, the neurophysiology of "optimal functioning" between them 861 differs. First-person shooters (FPSs), like Half-Life 2 (HL2) or Counter-Strike: Source (CS:S), 862 require more complex interactions than, for instance, Tetris or Pong. Virtually anyone could pick 863 up Tetris or Pong and play them right away, since the player only needs to push a few buttons. In 864 FPSs, players typically control the character with a combination of mouse and keyboard that

865

866

867

868

869

870

871

872

873

874

875

876

877

878

879

880

881

882

883

884

885

886

887

888

889

890

891

892 takes practice to use. Moreover, there are differences between the contents of the games used in the above-mentioned studies that require players to use different cognitive functions while playing. FPSs are three-dimensional games in which navigation is crucial, since the player only sees a small portion of the total space at any given time, and challenges are often hidden from view until they are close to the player or in their line of sight. In contrast, Tetris and Pong are two-dimensional and belong to the category of single-screen games, since all the relevant information is displayed simultaneously on the screen.

\section{Remaining issues and future research considerations}

It is important to note that most of the methodologies mentioned above cannot discriminate between internal states of flow and the external conditions that help induce a flow experience. Designing specific levels for the experiments (corresponding to under-challenged, flow, and over-challenged) that are directly related to the amount of skill-challenge balance does not guarantee that people will enter a flow state in the flow condition. The subjective experience of flow in the flow condition should be directly assessed using self-report flow scales in future studies to determine whether the participants were able to enter into a full flow state or not. One could consider adding objective measures other than neural or physiological markers to isolate the state of flow. One type of objective measure was designed by applying a secondary reactiontime task to assess the level of attentional focus during gameplay (Bombeke et al., 2018; Castellar et al., 2016; Huskey et al., 2018; Yun et al., 2017). Longer reaction times and more errors in the secondary task were reported to correlate with the subjective experience of flow (Castellar et al., 2016; Huskey et al., 2018).

The associations between performance and arousal (Yerkes \& Dodson, 1908) and flow and arousal (Peifer et al., 2014) suggest a close relationship between the flow experience and performance. The direction of this association has not yet been specifically investigated. It has been demonstrated that flow is a state of high concentration and that a sense of control can actually motivate subjects to improve their performance (Engeser \& Rheinberg, 2008; Jin, 2012; Landhäußer \& Keller, 2012). While the association between flow and optimal performance has been described in academic activities, music, and sports (Landhäußer \& Keller, 2012), few 
893 studies have reported a relationship in the gaming context (De Kock, 2014; Engeser \&

894 Rheinberg, 2008; Jin, 2012; Keller \& Bless, 2008; Yun et al., 2017). Some studies failed to find

895 an association between flow and optimal performance (Harris et al., 2016; Katahira et al., 2018;

896 Ulrich et al., 2016, 2014), reporting medium levels of performance during the flow condition. A

897 positive association was mostly reported in studies in which components of subjective flow were

898 directly measured instead of assessing behavioral levels of challenge and skills (De Kock, 2014;

899 Yun et al., 2017). The causal relationship between flow and performance cannot be tested in

900 typical cross-sectional experimental paradigms using difficulty manipulations; a longitudinal

901 design is required to assess causality (Keller \& Bless, 2008; Landhäußer \& Keller, 2012).

902 Performance could also provide an objective measure that, in combination with other measures

903 (e.g., physiological and neural indices, subjective self-reports, and secondary reaction times),

904 could precisely capture the actual emergence of flow. We argue that future studies should

905 consider using objective measures beside subjective scales and self-reports to capture the actual

906 emergence of flow.

\section{Conclusions}

908 This review provides an overview of physiological and neural findings during the flow

909 experience and integrates the empirical results to explain the underlying mechanisms of this

910 complex state. We separated distinct physiological and cognitive subfunctions involved in the

911 experience of flow. We conclude that flow is a positive mental state characterized by heightened

912 arousal, focused attention, synchronized activity in the brain's attention and reward networks and

913 results in automatic action control with less self-referential processing. Combining objective

914 measures with retrospective questionnaires seems essential to capture the actual emergence of

915 flow. The important role of focused attention during moments of flow necessitates employing

916 dual-task paradigms to distinguish internal flow phenomena from external situations inducing

917 flow.

\section{Acknowledgements}

919 We want to mention the collaborators of our EU-funded project VIRTUALTIMES - Exploring 920 and modifying the sense of time in virtual environments, namely the researchers in the following 921 groups with the principal investigators Kai Vogeley (Cologne), Anne Giersch (Strasbourg), Marc 922 Erich Latoschik, Jean-Luc Lugrin (Würzburg), Giulio Jacucci, Niklas Ravaja (Helsinki), Xavier

923 Palomer, Xavier Oromi (Barcelona). We thank one anonymous reviewer as well as Dr. Birte

924 Thissen for the constructive and detailed criticism of our manuscript that helped shaping the final 925 version. 


\section{References}

929

930

931

932

933

934

935

936

937

938

939

940

941

942

943

944

945

946

947

948

949

950

951

952

953

954

955

956

957

958

959

960

961

962

963

964

965

966

967

968

969

970

971

972
Aasman, J., Mulder, G., \& Mulder, L. J. M. (1987). Operator effort and the measurement of heart-rate variability. Human Factors, 29(2), 161-170.

Afergan, D., Peck, E. M., Solovey, E. T., Jenkins, A., Hincks, S. W., Brown, E. T., ... Jacob, R. J. K. (2014). Dynamic difficulty using brain metrics of workload. Proceedings of the 32nd Annual ACM Conference on Human Factors in Computing Systems - CHI '14, 3797-3806. https://doi.org/10.1145/2556288.2557230

Alvarez Igarzábal, F. (2019). Time and space in video games: A cognitive-formalist approach. Transcript.

Backs, R. W., \& Seljos, K. A. (1994). Metabolic and cardiorespiratory measures of mental effort: the effects of level of difficulty in a working memory task. International Journal of Psychophysiology, 16(1), 57-68.

Bakker, A. B. (2008). The work-related flow inventory: Construction and initial validation of the WOLF. Journal of Vocational Behavior, 72(3), 400-414. https://doi.org/10.1016/j.jvb.2007.11.007

Berkovich-Ohana, A., Dor-Ziderman, Y., Glicksohn, J., \& Goldstein, A. (2013). Alterations in the sense of time, space, and body in the mindfulness-trained brain: A neurophenomenologically-guided MEG study. Frontiers in Psychology, 4(DEC). https://doi.org/10.3389/fpsyg.2013.00912

Berta, R., Bellotti, F., De Gloria, A., Pranantha, D., \& Schatten, C. (2013). Electroencephalogram and Physiological Signal Analysis for Assessing Flow in Games. IEEE Transactions on Computational Intelligence and AI in Games, 5(2), 164-175.

Bian, Y., Yang, C., Gao, F., Li, H., Zhou, S., Li, H., ... Meng, X. (2016). A framework for physiological indicators of flow in VR games: construction and preliminary evaluation. Personal and Ubiquitous Computing, 20(5), 821-832. https://doi.org/10.1007/s00779-0160953-5

Bisson, N., Tobin, S., \& Grondin, S. (2012). Prospective and retrospective time estimates of children: A comparison based on ecological tasks. PLoS ONE, 7(3). https://doi.org/10.1371/journal.pone.0033049

Bombeke, K., Dongen, A. Van, Durnez, W., \& Anzolin, A. (2018). Do Not Disturb: Psychophysiological Correlates of Boredom, Flow and Frustration During VR Gaming. In Augmented Cognition: Intelligent Technologies (Vol. 10915, pp. 101-119). https://doi.org/10.1007/978-3-319-91470-1

Boucsein, W. (2012). Electrodermal activity. Springer Science \& Business Media.

Brom, C., Buchtová, M., Šisler, V., Děchtěrenko, F., Palme, R., \& Glenk, L. M. (2014). Flow, social interaction anxiety and salivary cortisol responses in serious games: A quasiexperimental study. Computers and Education, 79, 69-100. https://doi.org/10.1016/j.compedu.2014.07.001

Castellar, E. P. N., Antons, J.-N., Marinazzo, D., \& Van Looy, J. (2016). Being in the zone: Using behavioral and EEG recordings for the indirect assessment of flow. PeerJ Preprints, 4, 1-30. https://doi.org/https://doi.org/10.7287/peerj.preprints.2482v1

Cavanagh, J. F., \& Frank, M. J. (2014). Frontal Theta as a Mechanism for Affective and Effective Control. Psychophysiology, 18(8), 414-421. https://doi.org/10.1016/j.tics.2014.04.012.Frontal

Chanel, G., Rebetez, C., Bétrancourt, M., \& Pun, T. (2008). Boredom, engagement and anxiety 
973

974

975

976

977

978

979

980

981

982

983

984

985

986

987

988

989

990

991

992

993

994

995

996

997

998

999

1000

1001

1002

1003

1004

1005

1006

1007

1008

1009

1010

1011

1012

1013

1014

1015

1016

1017

1018

as indicators for adaptation to difficulty in games. Proceedings of the 12th International Conference on Entertainment and Media in the Ubiquitous Era - MindTrek '08, 13-17. https://doi.org/10.1145/1457199.1457203

Chanel, G., Rebetez, C., Bétrancourt, M., \& Pun, T. (2011). Emotion Assessment From Physiological Signals for Adaptation of Game Difficult. IEEE Transactions on Systems, Man, and Cybernetics-Part A: Systems and Humans, 41(6), 1052-1063.

Chen, J. (2006). Flow in games. https://doi.org/10.1145/1232743.1232769

Colzato, L. S., Wolters, G., \& Peifer, C. (2018). Transcutaneous vagus nerve stimulation (tVNS) modulates flow experience. Experimental Brain Research, 236(1), 253-257. https://doi.org/10.1007/s00221-017-5123-0

Craig, A. D. (2009). How do you feel - now? The anterior insula and human awareness. Nature Reviews Neuroscience, 10(1), 59-70. https://doi.org/10.1038/nrn2555

Critchley, H., \& Nagai, Y. (2013). Electrodermal Activity (EDA). In Encyclopedia of Behavioral Medicine (pp. 666-669). https://doi.org/10.1007/978-3-642-28753-4_100709

Csikszentmihalyi, M. (1975). Beyond boredom and anxiety. Jossey-Bass.

Csikszentmihalyi, M. (1990). Flow: The psychology of optimal experience. New York.

Csikszentmihalyi, M., Abuhamdeh, S., \& Nakamura, J. (2005). Flow. In Handbook of competence and motivation. (pp. 598-608). https://doi.org/10.1007/978-94-017-9088

Csikszentmihalyi, M., \& Csikszentmihalyi, I. S. (1992). Optimal experience: Psychological studies of flow in consciousness. https://doi.org/10.7551/mitpress/9780262013840.003.0010

Csikszentmihalyi, M., \& Larson, R. (1983). Validity and Reliability of the Experience-Sampling Method. In Flow and the Foundations of Positive Psychology (pp. 35-54). https://doi.org/10.1007/978-94-017-9088-8_3

Danckert, J., \& Merrifield, C. (2018). Boredom, sustained attention and the default mode network. Experimental Brain Research, 236(9), 2507-2518. https://doi.org/10.1007/s00221016-4617-5

De Kock, F. G. (2014). The neuropsychological measure (EEG) offlow under conditions of peak performance. Retrieved from http://uir.unisa.ac.za/handle/10500/14359

de Manzano, Ö., Cervenka, S., Jucaite, A., Hellenäs, O., Farde, L., \& Ullén, F. (2013). Individual differences in the proneness to have flow experiences are linked to dopamine D2-receptor availability in the dorsal striatum. NeuroImage, 67, 1-6. https://doi.org/10.1016/j.neuroimage.2012.10.072

de Manzano, Ö., Theorell, T., Harmat, L., \& Ullén, F. (2010). The Psychophysiology of Flow During Piano Playing. Emotion, 10(3), 301-311. https://doi.org/10.1037/a0018432

De Sampaio Barros, F., M., Araújo-Moreira, F., M., Trevelin, L., C., \& Radel, R. (2018). Flow experience and the mobilization of attentional resources. Cognitive, Affective and Behavioral Neuroscience, 18(4), 810-823. https://doi.org/10.3758/s13415-018-0606-4

Di Domenico, S. I., \& Ryan, R. M. (2017). The Emerging Neuroscience of Intrinsic Motivation: A New Frontier in Self-Determination Research. Frontiers in Human Neuroscience, 11(March), 1-14. https://doi.org/10.3389/fnhum.2017.00145

Dietrich, A. (2004). Neurocognitive mechanisms underlying the experience of flow. Consciousness and Cognition, 13(4), 746-761. https://doi.org/10.1016/j.concog.2004.07.002

Drachen, A., Nacke, L. E., Yannakakis, G., \& Pedersen, A. L. (2010). Correlation between heart rate, electrodermal activity and player experience in first-person shooter games. Proceedings of the 5th ACM SIGGRAPH Symposium on Video Games - Sandbox '10,

Peer] reviewing PDF | (2020:05:49318:3:0:NEW 11 Nov 2020) 
1019

1020

1021

1022

1023

1024

1025

1026

1027

1028

1029

1030

1031

1032

1033

1034

1035

1036

1037

1038

1039

1040

1041

1042

1043

1044

1045

1046

1047

1048

1049

1050

1051

1052

1053

1054

1055

1056

1057

1058

1059

1060

1061

1062

1063

1064

475(3), 49-54. https://doi.org/10.1145/1836135.1836143

Engeser, S., \& Rheinberg, F. (2008). Flow, performance and moderators of challenge-skill balance. Motivation and Emotion, 32(3), 158-172. https://doi.org/10.1007/s11031-0089102-4

Fong, C. J., Zaleski, D. J., \& Leach, J. K. (2015). The challenge-skill balance and antecedents of flow: A meta-analytic investigation. Journal of Positive Psychology, 10(5), 425-446. https://doi.org/10.1080/17439760.2014.967799

Gold, J., \& Ciorciari, J. (2019). A Transcranial Stimulation Intervention to Support Flow State Induction. Frontiers in Human Neuroscience, 13(August), 1-8. https://doi.org/10.3389/fnhum.2019.00274

Goldberg, I. I., Harel, M., \& Malach, R. (2006). When the Brain Loses Its Self: Prefrontal Inactivation during Sensorimotor Processing. Neuron, 50(2), 329-339. https://doi.org/10.1016/j.neuron.2006.03.015

Gusnard, D. A., Akbudak, E., Shulman, G. L., \& Raichle, M. E. (2001). Medial prefrontal cortex and self-referential mental activity: Relation to a default mode of brain function.

Proceedings of the National Academy of Sciences of the United States of America, 98(7), 4259-4264. https://doi.org/10.1073/pnas.071043098

Harmat, L., Manzano, Ö. De, Theorell, T., Högman, L., Fischer, H., \& Ullén, F. (2015). Physiological correlates of the flow experience during computer game playing. International Journal of Psychophysiology, 97(1), 1-7.

https://doi.org/10.1016/j.ijpsycho.2015.05.001

Harris, D. J., Vine, S. J., \& Wilson, M. R. (2016). Is flow really effortless? The complex role of effortful attention. Sport, Exercise, and Performance Psychology, 6(1), 103-114. https://doi.org/10.1037/spy0000083

Harris, D. J., Vine, S. J., \& Wilson, M. R. (2017). Neurocognitive mechanisms of the flow state. In Progress in Brain Research (1st ed., Vol. 234). https://doi.org/10.1016/bs.pbr.2017.06.012

Huskey, R., Craighead, B., Miller, M. B., \& Weber, R. (2018). Does intrinsic reward motivate cognitive control? a naturalistic-fMRI study based on the synchronization theory of flow. Cognitive, Affective and Behavioral Neuroscience, 18(5), 902-924. https://doi.org/10.3758/s13415-018-0612-6

IJsselsteijn, W., De Kort, Y., Poels, K., Jurgelionis, A., \& Bellotti, F. (2007). Characterising and Measuring User Experiences in Digital Games. International Conference on Advances in Computer Entertainment Technology, 620, 1-4. https://doi.org/10.1007/978-1-60761-580-4

Jackson, S. A., \& Eklund, R. C. (2004). The Flow Scales Manual. Fitness Information Technology.

Jackson, S. A., \& Marsh, H. W. (1996). Development and Validation of a Scale to Measure Optimal Experience: The Flow State Scale. Journal of Sport and Exercise Psychology, 18(1), 17-35. https://doi.org/10.1123/jsep.18.1.17

Jin, S. A. A. (2012). "Toward Integrative Models of Flow": Effects of Performance, Skill, Challenge, Playfulness, and Presence on Flow in Video Games. Journal of Broadcasting and Electronic Media, 56(2), 169-186. https://doi.org/10.1080/08838151.2012.678516

Ju, U., \& Wallraven, C. (2019). Manipulating and decoding subjective gaming experience during active gameplay: a multivariate, whole-brain analysis. NeuroImage, 188, 1-13.

https://doi.org/10.1016/j.neuroimage.2018.11.061

Kamath MV, F. EL. (1993). Power spectral analysis of heart rate variability: a noninvasive

Peer) reviewing PDF | (2020:05:49318:3:0:NEW 11 Nov 2020) 
1065

1066

1067

1068

1069

1070

1071

1072

1073

1074

1075

1076

1077

1078

1079

1080

1081

1082

1083

1084

1085

1086

1087

1088

1089

1090

1091

1092

1093

1094

1095

1096

1097

1098

1099

1100

1101

1102

1103

1104

1105

1106

1107

1108

1109

1110

signature of cardiac autonomic function. Crit Rev Biomed Eng, 21(3), 245-311.

Katahira, K., Yamazaki, Y., Yamaoka, C., Ozaki, H., Nakagawa, S., \& Nagata, N. (2018). EEG correlates of the flow state: A combination of increased frontal theta and moderate frontocentral alpha rhythm in the mental arithmetic task. Frontiers in Psychology, 9(MAR), 1-11. https://doi.org/10.3389/fpsyg.2018.00300

Keller, J., \& Bless, H. (2008). Flow and regulatory compatibility: An experimental approach to the flow model of intrinsic motivation. Personality and Social Psychology Bulletin, 34(2), 196-209. https://doi.org/10.1177/0146167207310026

Keller, J., Bless, H., Blomann, F., \& Kleinböhl, D. (2011). Physiological aspects of flow experiences: Skills-demand-compatibility effects on heart rate variability and salivary cortisol. Journal of Experimental Social Psychology, 47(4), 849-852.

https://doi.org/10.1016/j.jesp.2011.02.004

Keller, J., \& Blomann, F. (2008). Locus of control and the flow experience: An experimental analysis. European Journal of Personality, 22(7), 589-607. https://doi.org/10.1002/per.692

Khoshnoud, S., Shamsi, M., Nazari, M. A., \& Makeig, S. (2017). Different cortical source activation patterns in children with attention deficit hyperactivity disorder during a time reproduction task. Journal of Clinical and Experimental Neuropsychology, 40(7), 633-649. https://doi.org/10.1080/13803395.2017.1406897

Kivikangas, J. (2006). Psychophysiology of flow experience: an explorative study, Master's thesis. University of Helsinki.

Klasen, M., Weber, R., Kircher, T. T. J., Mathiak, K. A., \& Mathiak, K. (2012). Neural contributions to flow experience during video game playing. Social Cognitive and Affective Neuroscience, 7(4), 485-495. https://doi.org/10.1093/scan/nsr021

Klasen, M., Zvyagintsev, M., Weber, R., Mathiak, K. A., \& Mathiak, K. (2008). Think aloud during fMRI: Neuronal correlates of subjective experience in video games. Lecture Notes in Computer Science, 5294 LNCS(January), 132-138. https://doi.org/10.1007/978-3-54088322-7-13

Knierim, M. T., Rissler, R., Dorner, V., Maedche, A., \& Weinhardt, C. (2018). The Psychophysiology of Flow: A Systematic Review of Peripheral Nervous System Features. In Lecture Notes in Information Systems and Organisation (Vol. 25, pp. 109-120). https://doi.org/10.1007/978-3-319-67431-5_13

Kozhevnikov, M., Li, Y., Wong, S., Obana, T., \& Amihai, I. (2018). Do enhanced states exist? Boosting cognitive capacities through an action video-game. Cognition, 173(January), 93105. https://doi.org/10.1016/j.cognition.2018.01.006

Kramer, D. (2007). Predictions of Performance by EEG and Skin Conductance. Indiana Undergraduate Journal of Cognitive Science, 2, 3-13.

Kühn, S., Berna, F., Lüdtke, T., Gallinat, J., \& Moritz, S. (2018). Fighting depression: Action video game play may reduce rumination and increase subjective and objective cognition in depressed patients. Frontiers in Psychology, 9(FEB), 1-10. https://doi.org/10.3389/fpsyg.2018.00129

Laborde, S., Mosley, E., \& Thayer, J. F. (2017). Heart rate variability and cardiac vagal tone in psychophysiological research - Recommendations for experiment planning, data analysis, and data reporting. Frontiers in Psychology, 8(FEB), 1-18. https://doi.org/10.3389/fpsyg.2017.00213

Landhäußer, A., \& Keller, J. (2012). Flow and its affective, cognitive, and performance-related consequences. In Advances in flow research (pp. 65-85). Springer. 
1111

1112

1113

1114

1115

1116

1117

1118

1119

1120

1121

1122

1123

1124

1125

1126

1127

1128

1129

1130

1131

1132

1133

1134

1135

1136

1137

1138

1139

1140

1141

1142

1143

1144

1145

1146

1147

1148

1149

1150

1151

1152

1153

1154

1155

1156

Lang, P. J., Greenwald, M. K., Bradley, M. M., \& Hamm, A. O. (1993). Looking at pictures: Affective, facial, visceral, and behavioral reactions. Psychophysiology, 30(3), 261-273. https://doi.org/10.1111/j.1469-8986.1993.tb03352.x

Larsen, J. T., Berntson, G. G., Poehlmann, K. M., Ito, T. A., \& Cacioppo, J. T. (2008). The Psychophysiology of Emotion. In HANDBOOK OF EMOTIONS (pp. 180-195). https://doi.org/10.1249/00005768-200405001-00432

Léger, P. M., Davis, F. D., Cronan, T. P., \& Perret, J. (2014). Neurophysiological correlates of cognitive absorption in an enactive training context. Computers in Human Behavior, 34 , 273-283. https://doi.org/10.1016/j.chb.2014.02.011

Liknaitzky, P. (2017). The hyper-ordinary depression hypothesis, and mechanisms of cognitive rigidity in depression (or zen and art of reducing depressive cycle maintenance). Doctoral Dissertation of the University of Melbourne.

Liu, C., Agrawal, P., Sarkar, N., \& Chen, S. (2009). Dynamic difficulty adjustment in computer games through real-time anxiety-based affective feedback. International Journal of HumanComputer Interaction, 25(6), 506-529. https://doi.org/10.1080/10447310902963944

Malik, M., Camm, A. J., Bigger, J. T., Breithardt, G., Cerutti, S., Cohen, R. J., ... Singer, D. H. (1996). Heart rate variability. Standards of measurement, physiological interpretation, and clinical use. European Heart Journal, 17(3), 354-381. https://doi.org/10.1093/oxfordjournals.eurheartj.a014868

Mauri, M., Cipresso, P., Balgera, A., Villamira, M., \& Riva, G. (2011). Why Is Facebook So Successful? Psychophysiological Measures Describe a Core Flow State While Using Facebook. Cyberpsychology, Behavior, and Social Networking, 14(12), 723-731. https://doi.org/10.1089/cyber.2010.0377

Metin, B., Goktepe, A., Kaya, B., Serin, E., Tas, C., Dolu, F., \& Tarhan, N. (2017). EEG findings during flow state. The Journal of Neurobehavioral Sciences, (14), 1. https://doi.org/10.5455/JNBS.1496152464

Michailidis, L., Balaguer-Ballester, E., \& He, X. (2018). Flow and immersion in video games: The aftermath of a conceptual challenge. Frontiers in Psychology, 9(SEP), 1-8. https://doi.org/10.3389/fpsyg.2018.01682

Moller, A. C., Csikszentmihalyi, M., Nakamura, J., \& Deci, E. . (2007). Developing an experimental induction of flow. Poster Presented at the Society for Personality and Social Conference. Memphis, TN.

Moller, A. C., Meier, B. P., \& Wall, R. D. (2010). Developing an Experimental Induction of Flow: Effortless Action in the Lab. In Effortless attention: a new perspective in the cognitive science of attention and action (pp. 191-204). https://doi.org/10.7551/mitpress/9780262013840.003.0010

Moreno, M., Schnabel, R., Lancia, G., \& Woodruff, E. (2020). Between text and platforms: A case study on the real-time emotions \& psychophysiological indicators of video gaming and academic engagement. Education and Information Technologies, 25(3), 2073-2099. https://doi.org/10.1007/s10639-019-10031-3

Morris, J. S., Frith, C. D., Perrett, D. I., Rowland, D., Young, A. W., Calder, A. J., \& Dolan, R. J. (1996). A differential neural response in the human amygdala to fearful and happy facial expressions. Nature, 383(6603), 812-815. https://doi.org/10.1038/383812a0

Nacke, L. E. (2012). Flow in Games : Proposing a Flow Experience Model. Proceedings of the Workshop on Conceptualising, Operationalising and Measuring the Player Experience in Videogames at Fun and Games. Toulouse, France: ACM. 
1157

1158

1159

1160

1161

1162

1163

1164

1165

1166

1167

1168

1169

1170

1171

1172

1173

1174

1175

1176

1177

1178

1179

1180

1181

1182

1183

1184

1185

1186

1187

1188

1189

1190

1191

1192

1193

1194

1195

1196

1197

1198

1199

1200

1201

1202

Nacke, L. E., \& Lindley, C. A. (2008). Flow and immersion in first-person shooters: Measuring the player's gameplay experience. International Academic Conference on the Future of Game Design and Technology, Future Play: Research, Play, Share, 81-88. https://doi.org/10.1145/1496984.1496998

Nacke, L. E., \& Lindley, C. A. (2010). Affective Ludology, Flow and Immersion in a FirstPerson Shooter: Measurement of Player Experience. ArXiv Preprint, arXiv:1004. Retrieved from http://arxiv.org/abs/1004.0248

Nacke, L. E., Stellmach, S., \& Lindley, C. A. (2011). Electroencephalographic Assessment of Player Experience. Simulation \& Gaming, 42(5), 632-655. https://doi.org/10.1177/1046878110378140

Park, S., Sim, H., \& Lee, W. (2014). Dynamic Game difficulty Control by Using EEG-based emotion recognition. International Journal of Control and Automation, 7(3), 267-272. https://doi.org/10.14257/ijca.2014.7.3.26

Peifer, C. (2012). Psychophysiological correlates of flow-experience. In Advances in flow research (pp. 139-164). Springer.

Peifer, C., Schächinger, H., Engeser, S., \& Antoni, C. H. (2015). Cortisol effects on flowexperience. Psychopharmacology, 232(6), 1165-1173. https://doi.org/10.1007/s00213-0143753-5

Peifer, C., Schulz, A., Schächinger, H., Baumann, N., \& Antoni, C. H. (2014). The relation of flow-experience and physiological arousal under stress - Can u shape it? Journal of Experimental Social Psychology, 53, 62-69. https://doi.org/10.1016/j.jesp.2014.01.009

Posner, M. I., Inhoff, A. W., Friedrich, F. J., \& Cohen, A. (1987). Isolating attentional mechanisms: A cognitive-anatomical analysis. Psychobiology, 15(2), 107-112.

Raichle, M. E., MacLeod, A. M., Snyder, A. Z., Powers, W. J., Gusnard, D. A., \& Shulman, G. L. (2001). A default mode of brain function. Proceedings of the National Academy of Sciences, 98(2), 676-682. https://doi.org/10.1073/pnas.98.2.676

Raz, A., \& Buhle, J. (2006). Typologies of attentional networks. Nature Reviews Neuroscience, 7(5), 367-379. https://doi.org/10.1038/nrn1903

Reyes del Paso, G. A., Langewitz, W., Mulder, L. J. M., van Roon, A., \& Duschek, S. (2013). The utility of low frequency heart rate variability as an index of sympathetic cardiac tone: A review with emphasis on a reanalysis of previous studies. Psychophysiology, 50(5), 477487. https://doi.org/10.1111/psyp.12027

Rheinberg, F., \& Vollmeyer, R. (2003). erschien 2003 in Zeitschrift für Psychologie, 4, 161-170. Zeitschrift Für Psychologie, 4, 4, 161-170.

Sadlo, G. (2016). Towards a Neurobiological Understanding of Reduced Self-Awareness During Flow: An Occupational Science Perspective. In Flow Experience: Empirical Research and Applications (pp. 375-388). https://doi.org/10.1007/978-3-319-28634-1

Salen, K., \& Zimmerman, E. (2003). Rules of Play: Game Design Fundamentals. The MIT Press.

Saproo, S., Shih, V., Jangraw, D. C., \& Sajda, P. (2016). Neural mechanisms underlying catastrophic failure in human-machine interaction during aerial navigation. Journal of Neural Engineering, 13(6). https://doi.org/10.1088/1741-2560/13/6/066005

Schell, J. (2008). The art of game design: A book of lenses. Elsevier/Morgan Kaufmann.

Shaffer, F., \& Ginsberg, J. P. (2017). An Overview of Heart Rate Variability Metrics and Norms. Frontiers in Public Health, 5(September), 1-17. https://doi.org/10.3389/fpubh.2017.00258

Sherry, J.L., Rosaen, S., Bowman, N., Huh, S. (2006). Cognitive skill predicts video game

Peer) reviewing PDF | (2020:05:49318:3:0:NEW 11 Nov 2020) 
1203

1204

1205

1206

1207

1208

1209

1210

1211

1212

1213

1214

1215

1216

1217

1218

1219

1220

1221

1222

1223

1224

1225

1226

1227

1228

1229

1230

1231

1232

1233

1234

1235

1236

1237

1238

1239

1240

1241

1242

1243

1244

1245

1246

1247

1248

ability. Annual Meeting of the International Communication Association., Dresden. Dresden.

Shin, N. (2006). Online learner's "flow" experience: An empirical study. British Journal of Educational Technology, 37(5), 705-720. https://doi.org/10.1111/j.14678535.2006.00641.x

Sinnett, S., Jäger, J., Singer, S. M., \& Antonini Philippe, R. (2020). Flow States and Associated Changes in Spatial and Temporal Processing. Frontiers in Psychology, 11(March), 1-13. https://doi.org/10.3389/fpsyg.2020.00381

Sridharan, D., Levitin, D. J., \& Menon, V. (2008). A critical role for the right fronto-insular cortex in switching between central-executive and default-mode networks. Proceedings of the National Academy of Sciences of the United States of America, 105(34), 12569-12574. https://doi.org/10.1073/pnas.0800005105

Tian, Y., Bian, Y., Han, P., Wang, P., Gao, F., \& Chen, Y. (2017). Physiological signal analysis for evaluating flow during playing of computer games of varying difficulty. Frontiers in Psychology, 8(JUL), 1-10. https://doi.org/10.3389/fpsyg.2017.01121

Tobin, S., Bisson, N., \& Grondin, S. (2010). An ecological approach to prospective and retrospective timing of long durations: A study involving gamers. PLOS ONE, 5(2), 16-18. https://doi.org/10.1371/journal.pone.0009271

Tozman, T., Magdas, E. S., MacDougall, H. G., \& Vollmeyer, R. (2015). Understanding the psychophysiology of flow: A driving simulator experiment to investigate the relationship between flow and heart rate variability. Computers in Human Behavior, 52, 408-418. https://doi.org/10.1016/j.chb.2015.06.023

Tozman, T., \& Peifer, C. (2016). Experimental paradigms to investigate flow-experience and its psychophysiology: Inspired from stress theory and research. Flow Experience: Empirical Research and Applications, 329-350. https://doi.org/10.1007/978-3-319-28634-1_20

Ullén, F., de Manzano, Ö., Almeida, R., Magnusson, P. K. E., Pedersen, N. L., Nakamura, J., ... Madison, G. (2012). Proneness for psychological flow in everyday life: Associations with personality and intelligence. Personality and Individual Differences, 52(2), 167-172. https://doi.org/10.1016/j.paid.2011.10.003

Ullén, F., de Manzano, Ö., Theorell, T., \& Harmat, L. (2010). The Physiology of Effortless Attention: Correlates of State Flow and Flow Proneness. In Effortless attention: a new perspective in the cognitive science of attention and action (pp. 205-218). https://doi.org/10.7551/mitpress/9780262013840.003.0011

Ulrich, M., Keller, J., \& Grön, G. (2016). Neural signatures of experimentally induced flow experiences identified in a typical fMRI block design with BOLD imaging. Social Cognitive and Affective Neuroscience, 11(3), 496-507. https://doi.org/10.1093/scan/nsv133

Ulrich, M., Keller, J., Hoenig, K., Waller, C., \& Grön, G. (2014). Neural correlates of experimentally induced flow experiences. NeuroImage, 86, 194-202. https://doi.org/10.1016/j.neuroimage.2013.08.019

Ulrich, M., Niemann, J., Boland, M., Kammer, T., Niemann, F., \& Grön, G. (2018). The neural correlates of flow experience explored with transcranial direct current stimulation. Experimental Brain Research, 236(12), 3223-3237. https://doi.org/10.1007/s00221-0185378-0

Veltman, J. A., \& Gaillard, A. W. K. (1998). Physiological workload reactions to increasing levels of task difficulty. Ergonomics, 41(5), 656-669. https://doi.org/10.1080/001401398186829 
1249 Vogel, D., Falter-Wagner, C. M., Schoofs, T., Krämer, K., Kupke, C., \& Vogeley, K. (2019).

1250

1251

1252

1253

1254

1255

1256

1257

1258

1259

1260

1261

1262

1263

1264

1265

1266

1267

1268

1269

1270

1271

1272

1273

1274

1275

1276

1277

1278

1279

1280

1281

1282

1283

1284

1285

1286

1287

1288

1289

1290

1291

1292

1293

1294

Interrupted Time Experience in Autism Spectrum Disorder: Empirical Evidence from Content Analysis. Journal of Autism and Developmental Disorders, 49(1), 22-33. https://doi.org/10.1007/s10803-018-3771-y

Vogel, D., Krämer, K., Schoofs, T., Kupke, C., \& Vogeley, K. (2018). Disturbed Experience of Time in Depression-Evidence from Content Analysis. Frontiers in Human Neuroscience, 12(February), 1-10. https://doi.org/10.3389/fnhum.2018.00066

Wang, C. C., \& Hsu, M. C. (2014). An exploratory study using inexpensive electroencephalography (EEG) to understand flow experience in computer-based instruction. Information and Management, 51(7), 912-923. https://doi.org/10.1016/j.im.2014.05.010

Waterink, W., \& van Boxtel, A. (1994). Facial and jaw-elevator EMG activity in relation to changes in performance level during a sustained information processing task. Biological Psychology, 37(3), 183-198. https://doi.org/10.1016/0301-0511(94)90001-9

Weber, R., Alicea, B., Huskey, R., \& Mathiak, K. (2018). Network dynamics of attention during a naturalistic behavioral paradigm. Frontiers in Human Neuroscience, 12(May), 1-14. https://doi.org/10.3389/fnhum.2018.00182

Weber, R., Huskey, R., \& Craighead, B. (2016). FLOW EXPERIENCES AND WELL-BEING : A Media Neuroscience Perspective. In Handbook of media use and well-being: International perspectives on theory and research on positive media effects. Routledge.

Weber, R., Tamborini, R., Westcott-Baker, A., \& Kantor, B. (2009). Theorizing flow and media enjoyment as cognitive synchronization of attentional and reward networks. Communication Theory, 19(4), 397-422. https://doi.org/10.1111/j.1468-2885.2009.01352.x

Wittmann, M. (2015). Modulations of the experience of self and time. Consciousness and Cognition, 38, 172-181. https://doi.org/10.1016/j.concog.2015.06.008

Wittmann, M. (2018). Altered States of Consciousness: Experiences Out of Time and Self. MIT Press.

Wittmann, M., Simmons, A. N., Aron, J. L., \& Paulus, M. P. (2010). Accumulation of neural activity in the posterior insula encodes the passage of time. Neuropsychologia, 48(10), 3110-3120. https://doi.org/10.1016/j.neuropsychologia.2010.06.023

Wolf, S., Brölz, E., Keune, P. M., Wesa, B., Hautzinger, M., Birbaumer, N., \& Strehl, U. (2015). Motor skill failure or flow-experience? Functional brain asymmetry and brain connectivity in elite and amateur table tennis players. Biological Psychology, 105, 95-105. https://doi.org/10.1016/j.biopsycho.2015.01.007

Yerkes, R. M., \& Dodson, J. D. (1908). The relation of strength of stimulus to rapidity of habit-formation. Journal of Comparative Neurology and Psychology, 18(5), 459-482.

Yoshida, K., Asakawa, K., Yamauchi, T., Sakuraba, S., Sawamura, D., Murakami, Y., \& Sakai, S. (2013). The flow state scale for occupational tasks: Development, reliability, and validity. Hong Kong Journal of Occupational Therapy, 23(2), 54-61. https://doi.org/10.1016/j.hkjot.2013.09.002

Yoshida, K., Sawamura, D., Inagaki, Y., Ogawa, K., Ikoma, K., \& Sakai, S. (2014). Brain activity during the flow experience: A functional near-infrared spectroscopy study. Neuroscience Letters, 573, 30-34. https://doi.org/10.1016/j.neulet.2014.05.011

Yun, K., Doh, S., Carrus, E., Wu, D., \& Shimojo, S. (2017). Being in the zone : Flow state and the underlying neural dynamics in video game playing. ArXiv [Preprint]., arXiv:1711, 131.

Peer) reviewing PDF | (2020:05:49318:3:0:NEW 11 Nov 2020) 


\section{Table 1 (on next page)}

Table 1: Studies on peripheral-physiological correlates of the flow state 
Table 1: Studies on peripheral-physiological correlates of the flow state

\begin{tabular}{|c|c|c|c|c|c|c|c|}
\hline Ref. & $\underset{\text { subjects }}{\mathbf{N}}$ & $\begin{array}{l}\text { Age } \\
\text { mean/ } \\
\text { range }\end{array}$ & Sample & $\begin{array}{l}\text { Experiment } \\
\text { type }\end{array}$ & Design & Measure & $\begin{array}{l}\text { Peripheral-physiological } \\
\text { correlates of flow }\end{array}$ \\
\hline $\begin{array}{l}\text { Kivikangas } \\
(2006)\end{array}$ & $32(\mathrm{~m})$ & $17-34$ & $\begin{array}{l}\text { Healthy } \\
\text { students }\end{array}$ & $\begin{array}{l}\text { FPS game: } \\
\text { Halo: combat } \\
\text { evolved }\end{array}$ & $\begin{array}{l}40 \text { minutes } \\
\text { gameplay }\end{array}$ & $\begin{array}{l}\text { FEMG, } \\
\text { EDA }\end{array}$ & $\begin{array}{l}\text { Negative correlations } \\
\text { between CS activity \& flow }\end{array}$ \\
\hline $\begin{array}{l}\text { Chanel et al. } \\
\text { (2008) }\end{array}$ & $20(7 f)$ & 27 & $\begin{array}{l}\text { Healthy } \\
\text { participants }\end{array}$ & Tetris game & $\begin{array}{l}5 \text { minutes } \\
\text { Under-challenged } \\
\text { Flow } \\
\text { Over-challenged }\end{array}$ & $\begin{array}{l}\text { EDA, } \\
\text { BP, Res, } \\
T\end{array}$ & $\begin{array}{l}\text { Increase in EDA \& HR with } \\
\text { increasing difficulty }\end{array}$ \\
\hline $\begin{array}{l}\text { Nacke \& } \\
\text { Lindley } \\
(2008)\end{array}$ & $25(\mathrm{~m})$ & $19-38$ & $\begin{array}{l}\text { Healthy } \\
\text { students }\end{array}$ & $\begin{array}{l}\text { FPS game: } \\
\text { Half-Life } 2\end{array}$ & $\begin{array}{l}10 \text { minutes } \\
\text { Under-challenged } \\
\text { Immersion } \\
\text { Flow }\end{array}$ & $\begin{array}{l}\text { FEMG, } \\
\text { EDA }\end{array}$ & $\begin{array}{l}\text { Highest ZM activity \& EDA } \\
\text { values in the flow condition }\end{array}$ \\
\hline
\end{tabular}

\begin{tabular}{|c|c|c|c|c|c|c|c|}
\hline $\begin{array}{l}\text { Drachen } \\
\text { et al. }(2010)\end{array}$ & 16 & - & - & $\begin{array}{l}\text { FPS games: } \\
\text { Prey, } \\
\text { Doom3, } \\
\text { Biochock }\end{array}$ & $\begin{array}{l}20 \text { minutes } \\
\text { gameplay }\end{array}$ & $\begin{array}{l}\text { EDA, } \\
\text { HR }\end{array}$ & $\begin{array}{l}\text { Negative correlation between } \\
\text { HR \& flow subscale score }\end{array}$ \\
\hline
\end{tabular}

\begin{tabular}{|c|c|c|c|c|c|c|c|}
\hline $\begin{array}{l}\text { Chanel et al. } \\
\text { (2011) }\end{array}$ & $20(7 f)$ & 27 & $\begin{array}{l}\text { Healthy } \\
\text { participants }\end{array}$ & Tetris game & $\begin{array}{l}5 \text { minutes } \\
\text { Under-challenged } \\
\text { Flow } \\
\text { Over-challenged }\end{array}$ & $\begin{array}{l}\text { EDA, } \\
\text { BP, Res, } \\
\text { T, EEG }\end{array}$ & $\begin{array}{l}\text { Least LF-HRV in the flow } \\
\text { condition }\end{array}$ \\
\hline
\end{tabular}

\begin{tabular}{|c|c|c|c|c|c|c|c|}
\hline $\begin{array}{l}\text { Keller et al. } \\
(2011)\end{array}$ & $\begin{array}{l}8(4 f) \\
61(m)\end{array}$ & - & $\begin{array}{l}\text { Healthy } \\
\text { students }\end{array}$ & $\begin{array}{l}\text { Computerized } \\
\text { knowledge } \\
\text { task, Tetris } \\
\text { game }\end{array}$ & $\begin{array}{l}\text { Under-challenged } \\
\text { Flow } \\
\text { Over-challenged }\end{array}$ & $\begin{array}{l}\text { HRV, } \\
\text { Cortisol }\end{array}$ & $\begin{array}{l}\text { Lower HRV \& higher cortisol } \\
\text { in the flow condition }\end{array}$ \\
\hline
\end{tabular}

$\begin{array}{lllllll}\begin{array}{l}\text { Peifer et al. 22(m) } \\ (2014)\end{array} & 20-34 & \begin{array}{l}\text { Healthy } \\ \text { students }\end{array} & \begin{array}{l}\text { Cabin Air } \\ \text { Management } \\ \text { System } \\ \text { software }\end{array} & \begin{array}{l}60 \text { minutes } \\ \text { performance }\end{array} & \begin{array}{l}\text { ECG, } \\ \text { Cortisol }\end{array} & \begin{array}{l}\text { Inverted U-shaped } \\ \text { relationship of LF-HRV \& } \\ \text { cortisol level with the flow } \\ \text { experience; positive linear } \\ \text { relationship between HF- } \\ \text { HRV \& flow }\end{array} \\ & & & & \\ & & & & \end{array}$

\begin{tabular}{|c|c|c|c|c|c|c|c|}
\hline $\begin{array}{l}\text { Leger et al. } \\
(2014)\end{array}$ & 36 & - & $\begin{array}{l}\text { Healthy } \\
\text { students }\end{array}$ & $\begin{array}{l}\text { Enterprise } \\
\text { Resource } \\
\text { Planning } \\
\text { software }\end{array}$ & $\begin{array}{l}\text { Under-challenged } \\
\text { Flow } \\
\text { Over-challenged }\end{array}$ & $\begin{array}{l}\text { ECG, } \\
\text { EDA, } \\
\text { EEG }\end{array}$ & $\begin{array}{l}\text { Smaller variation of EDA, } \\
\text { lower HR, \& higher HRV in } \\
\text { the flow condition }\end{array}$ \\
\hline $\begin{array}{l}\text { Harmat et al. } \\
(2015)\end{array}$ & $77(40 f)$ & 27 & $\begin{array}{l}\text { Healthy } \\
\text { subjects }\end{array}$ & Tetris game & $\begin{array}{l}6 \text { minutes } \\
\text { Under-challenged } \\
\text { Flow } \\
\text { Over-challenged }\end{array}$ & $\begin{array}{l}\text { fNIRS, } \\
\text { ECG, } \\
\text { Res }\end{array}$ & $\begin{array}{l}\text { Larger RD \& lower LF-HRV } \\
\text { in the flow condition }\end{array}$ \\
\hline
\end{tabular}


Table 1: Studies on peripheral-physiological correlates of the flow state

\begin{tabular}{|c|c|c|c|c|c|c|c|}
\hline Ref. & $\begin{array}{l}\mathbf{N} \\
\text { subjects }\end{array}$ & $\begin{array}{l}\text { Age } \\
\text { mean/ } \\
\text { range }\end{array}$ & Sample & $\begin{array}{l}\text { Experiment } \\
\text { type }\end{array}$ & Design & Measure & $\begin{array}{l}\text { Peripheral-physiological } \\
\text { correlates of flow }\end{array}$ \\
\hline $\begin{array}{l}\text { Tozman et al. } \\
(2015)\end{array}$ & $18(6 f)$ & 19 & $\begin{array}{l}\text { Healthy } \\
\text { students }\end{array}$ & $\begin{array}{l}\text { Sporting race } \\
\text { game: } \\
\text { Rfactor }\end{array}$ & $\begin{array}{l}6 \text { minutes } \\
\text { Under-challenged } \\
\text { Flow } \\
\text { Over-challenged }\end{array}$ & ECG & $\begin{array}{l}\text { Negative linear relationship } \\
\text { between LF-HRV \& flow in } \\
\text { the flow condition; Inverted } \\
\text { U-shaped relation between } \\
\text { LF-HRV / HF-HRV \& flow } \\
\text { in the anxiety condition }\end{array}$ \\
\hline $\begin{array}{l}\text { Bian et al. } \\
(2016)\end{array}$ & $36(16 f)$ & $20-27$ & $\begin{array}{l}\text { Healthy } \\
\text { adults }\end{array}$ & $\begin{array}{l}\text { VR game: } \\
\text { Air } \\
\text { Bombardment }\end{array}$ & $\begin{array}{l}6 \text { minutes } \\
\text { gameplay }\end{array}$ & $\begin{array}{l}\text { ECG, } \\
\text { Res, } \\
\text { FEMG }\end{array}$ & $\begin{array}{l}\text { Inverted U-shaped } \\
\text { relationship between LF- } \\
\text { HRV, HF-HRV, \& flow }\end{array}$ \\
\hline $\begin{array}{l}\text { Harris et al. } \\
(2016)\end{array}$ & $33(10 f)$ & 20 & $\begin{array}{l}\text { Healthy } \\
\text { students }\end{array}$ & $\begin{array}{l}\text { Simulated car } \\
\text { racing game }\end{array}$ & $\begin{array}{l}\text { Under-challenged } \\
\text { Flow } \\
\text { Over-challenged }\end{array}$ & $\begin{array}{l}\text { ECG, eye } \\
\text { gaze } \\
\text { position }\end{array}$ & $\begin{array}{l}\text { Lower SD of horizontal gaze } \\
\text { position \& Lower HF-HRV in } \\
\text { the flow condition }\end{array}$ \\
\hline $\begin{array}{l}\text { Ulrich et al. } \\
\text { (2016) }\end{array}$ & $23(\mathrm{~m})$ & 24 & $\begin{array}{l}\text { Healthy } \\
\text { students }\end{array}$ & $\begin{array}{l}\text { Mental } \\
\text { arithmetic } \\
\text { task }\end{array}$ & $\begin{array}{l}30 \text { seconds } \\
\text { Under-challenged } \\
\text { Flow } \\
\text { Over-challenged }\end{array}$ & $\begin{array}{l}\text { fMRI, } \\
\text { EDA }\end{array}$ & $\begin{array}{l}\text { Greater EDA in the flow } \\
\text { condition }\end{array}$ \\
\hline $\begin{array}{l}\text { Tian et al. } \\
(2017)\end{array}$ & $40(27 f)$ & $17-24$ & $\begin{array}{l}\text { Healthy } \\
\text { students }\end{array}$ & $\begin{array}{l}\text { Blocmania } \\
\text { 3D } \\
\text { game }\end{array}$ & $\begin{array}{l}6 \text { minutes } \\
\text { Under-challenged } \\
\text { Flow } \\
\text { Over-challenged }\end{array}$ & $\begin{array}{l}\text { ECG, } \\
\text { Res, } \\
\text { EDA }\end{array}$ & $\begin{array}{l}\text { Faster respiratory rate, } \\
\text { increased } \mathrm{RD}, \text { moderate } \mathrm{HR}, \\
\text { moderate } \mathrm{HRV}, \& \text { moderate } \\
\text { EDA in the flow condition }\end{array}$ \\
\hline $\begin{array}{l}\text { De Sampaio } \\
\text { Barros et al. } \\
(2018)\end{array}$ & $20(7 f)$ & 26 & $\begin{array}{l}\text { Healthy } \\
\text { adults }\end{array}$ & $\begin{array}{l}\text { Tetris, Pong } \\
\text { games }\end{array}$ & $\begin{array}{l}3 \text { minutes } \\
\text { Under-challenged } \\
\text { Flow } \\
\text { Over-challenged } \\
\text { Autonomy }\end{array}$ & $\begin{array}{l}\text { ECG, } \\
\text { Res, } \\
\text { NIRS }\end{array}$ & $\begin{array}{l}\text { Lower HRV in the autonomy } \\
\text { condition }\end{array}$ \\
\hline $\begin{array}{l}\text { Kozhevnikov } \\
\text { et al. (2018) }\end{array}$ & $56(17 f)$ & - & $\begin{array}{l}\text { Healthy } \\
\text { students }\end{array}$ & $\begin{array}{l}\text { Unreal } \\
\text { Tournament } \\
2004 \text { game }\end{array}$ & $\begin{array}{l}30 \text { minutes } \\
\text { Under-challenged } \\
\text { Flow } \\
\text { Over-challenged }\end{array}$ & ECG & $\begin{array}{l}\text { Lower HF-HRV in the flow } \\
\text { condition }\end{array}$ \\
\hline $\begin{array}{l}\text { Moreno et al. } \\
(2020)\end{array}$ & 1 & 27 & $\begin{array}{l}\text { Expert } \\
\text { gamer }\end{array}$ & Portal game & $\begin{array}{l}45 \text { minutes } \\
\text { gameplay }\end{array}$ & $\begin{array}{l}\text { EDA, } \\
\text { EEG }\end{array}$ & $\begin{array}{l}\text { Increased EDA during } \\
\text { moments of goal attainment }\end{array}$ \\
\hline
\end{tabular}

$\mathrm{ECG}=$ electrocardiography; EEG = electroencephalography; FEMG = facial electromyography; EDA = electrodermal activity; $\mathrm{BP}=$ blood pressure; $\mathrm{T}=$ temperature; $\mathrm{HR}=$ heart rate; $\mathrm{HP}=$ heart period; $\mathrm{ZM}=$ zygomaticus major; $\mathrm{CS}=$ corrugator supercilii; HRV = heart rate variability; LF-HRV = low-frequency heart-rate variability; HF-HRV = highfrequency heart-rate variability; Res = respiration; $\mathrm{RD}=$ respiratory depth; fNIRS = functional near-infrared spectroscopy; NIRS = near-infrared spectroscopy; fMRI = functional magnetic resonance imaging; FPS $=$ first person shooter; SD = standard deviation; $\mathrm{m}=$ male; $\mathrm{f}=$ female 
Table 2 (on next page)

Table 2: Studies on neural correlates of the flow state: brain imaging investigations 
1

Table 2: Studies on neural correlates of the flow state: brain imaging investigations

\begin{tabular}{|c|c|c|c|c|c|c|c|}
\hline Ref. & $\begin{array}{l}\mathbf{N} \\
\text { subjects }\end{array}$ & $\begin{array}{l}\text { Age } \\
\text { mean/ } \\
\text { range }\end{array}$ & Sample & $\begin{array}{l}\text { Experiment } \\
\text { type }\end{array}$ & Design & Measure & Neural correlates of flow \\
\hline $\begin{array}{l}\text { Klasen et al. } \\
(2008)\end{array}$ & 18 & - & - & $\begin{array}{l}\text { FPS game: } \\
\text { Counter } \\
\text { Strike }\end{array}$ & $\begin{array}{l}12 \text { minutes } \\
\text { gameplay }\end{array}$ & fMRI & $\begin{array}{l}\text { Correlation between game } \\
\text { pleasure, cerebro-thalamic } \\
\text { motor, \& visual network } \\
\text { activity }\end{array}$ \\
\hline $\begin{array}{l}\text { Klasen et al. } \\
(2012)\end{array}$ & $13(\mathrm{~m})$ & $18-26$ & $\begin{array}{l}\text { Healthy } \\
\text { students }\end{array}$ & $\begin{array}{l}\text { FPS game : } \\
\text { Tactical Ops } \\
\text { Assault on } \\
\text { Terror }\end{array}$ & $\begin{array}{l}12 \text { minutes } \\
\text { gameplay }\end{array}$ & fMRI & $\begin{array}{l}\text { Activation of somatosensory } \\
\text { networks \& motor areas } \\
\text { during situations with } \\
\text { enhanced probability of flow }\end{array}$ \\
\hline $\begin{array}{l}\text { Ulrich et al. } \\
\text { (2014) }\end{array}$ & $27(\mathrm{~m})$ & 23 & $\begin{array}{l}\text { Healthy } \\
\text { students }\end{array}$ & $\begin{array}{l}\text { Mental } \\
\text { arithmetic } \\
\text { task }\end{array}$ & $\begin{array}{l}184 \text { seconds } \\
\text { Under-challenged } \\
\text { Flow } \\
\text { Over-challenged }\end{array}$ & $\begin{array}{l}\text { Perfusion } \\
\text { MRI }\end{array}$ & $\begin{array}{l}\text { Increased activity in the left } \\
\text { IFG, left putamen, \& } \\
\text { posterior cortical regions as } \\
\text { well as decrease in MPFC and } \\
\text { AMY in the flow condition }\end{array}$ \\
\hline $\begin{array}{l}\text { Yoshida et } \\
\text { al. (2014) }\end{array}$ & $20(10 f)$ & $21-25$ & $\begin{array}{l}\text { Healthy } \\
\text { students }\end{array}$ & Tetris game & $\begin{array}{l}4 \text { minutes } \\
\text { Under-challenged } \\
\text { Flow }\end{array}$ & fNIRS & $\begin{array}{l}\text { Higher activation of VLPFC } \\
\text { in the flow condition }\end{array}$ \\
\hline $\begin{array}{l}\text { Harmat et al. } \\
(2015)\end{array}$ & $77(40 f)$ & 27 & $\begin{array}{l}\text { Healthy } \\
\text { subjects }\end{array}$ & Tetris game & $\begin{array}{l}6 \text { minutes Under- } \\
\text { challenged } \\
\text { Flow } \\
\text { Over-challenged }\end{array}$ & $\begin{array}{l}\text { fNIRS, } \\
\text { ECG, } \\
\text { Res }\end{array}$ & $\begin{array}{l}\text { No association between } \\
\text { frontal cortical oxygenation \& } \\
\text { flow }\end{array}$ \\
\hline $\begin{array}{l}\text { Ulrich et al. } \\
\text { (2016) }\end{array}$ & $23(\mathrm{~m})$ & 24 & $\begin{array}{l}\text { Healthy } \\
\text { students }\end{array}$ & $\begin{array}{l}\text { Mental } \\
\text { arithmetic } \\
\text { task }\end{array}$ & $\begin{array}{l}30 \text { seconds } \\
\text { Under-challenged } \\
\text { Flow } \\
\text { Over-challenged }\end{array}$ & $\begin{array}{l}\text { fMRI } \\
\text { EDA }\end{array}$ & $\begin{array}{l}\text { Increased activity in the left } \\
\text { IFG, left putamen, \& } \\
\text { posterior cortical regions in } \\
\text { the flow condition; decreased } \\
\text { activity in MPFC, PCC and } \\
\text { AMY in the flow condition }\end{array}$ \\
\hline $\begin{array}{l}\text { De Sampaio } \\
\text { Barros et al. } \\
(2018)\end{array}$ & $20(7 f)$ & 26 & $\begin{array}{l}\text { Healthy } \\
\text { adults }\end{array}$ & $\begin{array}{l}\text { Tetris, Pong } \\
\text { games }\end{array}$ & $\begin{array}{l}3 \text { minutes } \\
\text { Under-challenged } \\
\text { Flow } \\
\text { Over-challenged } \\
\text { Autonomy }\end{array}$ & $\begin{array}{l}\text { ECG, } \\
\text { Res, } \\
\text { NIRS }\end{array}$ & $\begin{array}{l}\text { Higher activation in lateral } \\
\text { PFC \& deactivation in MPFC } \\
\text { in the autonomy condition }\end{array}$ \\
\hline $\begin{array}{l}\text { Ulrich et al., } \\
(2018)\end{array}$ & $22(\mathrm{~m})$ & 24.9 & $\begin{array}{l}\text { Healthy } \\
\text { students }\end{array}$ & $\begin{array}{l}\text { Mental } \\
\text { arithmetic } \\
\text { task }\end{array}$ & $\begin{array}{l}170 \text { seconds } \\
\text { Under-challenged } \\
\text { Flow } \\
\text { Over-challenged }\end{array}$ & $\begin{array}{l}\text { Perfusion } \\
\text { MRI, } \\
\text { tDCS }\end{array}$ & $\begin{array}{l}\text { Increase in the flow index of } \\
\text { lower-flow group under } \\
\text { anodal midfrontal tDCS } \\
\text { stimulation \& stronger } \\
\text { deactivation of AMY }\end{array}$ \\
\hline
\end{tabular}


26

Table 2: Studies on neural correlates of the flow state: brain imaging investigations

\begin{tabular}{|c|c|c|c|c|c|c|c|}
\hline Ref. & $\underset{\text { subjects }}{\mathbf{N}}$ & $\begin{array}{l}\text { Age } \\
\text { mean/ } \\
\text { range }\end{array}$ & Sample & $\begin{array}{l}\text { Experiment } \\
\text { type }\end{array}$ & Design & Measure & Neural correlates of flow \\
\hline \multirow{3}{*}{$\begin{array}{l}\text { Gold \& } \\
\text { Ciorciari } \\
(2019)\end{array}$} & $11(\mathrm{~m})$ & \multirow[t]{3}{*}{$29-31$} & \multirow{3}{*}{$\begin{array}{l}\text { Trained \& } \\
\text { untrained } \\
\text { gamers }\end{array}$} & \multirow{3}{*}{$\begin{array}{l}\text { FPS games: } \\
\text { Counter Strike } \\
\text { Global } \\
\text { Offensive, } \\
\text { Battlefield 4, } \\
\text { Tetris game }\end{array}$} & \multirow{3}{*}{$\begin{array}{l}20 \text { minutes \& } 3 \\
\text { minutes } \\
\text { Under-challenged } \\
\text { Flow } \\
\text { Over-challenged }\end{array}$} & \multirow{3}{*}{ tDCS } & \multirow{3}{*}{$\begin{array}{l}\text { Higher level of flow after the } \\
\text { active tDCS over DLPFC \& } \\
\text { right parietal cortex }\end{array}$} \\
\hline & 21(11f) & & & & & & \\
\hline & & & & & & & \\
\hline $\begin{array}{l}\text { Ju \& } \\
\text { Wallravan } \\
(2019)\end{array}$ & $31(\mathrm{~m})$ & 24.8 & $\begin{array}{l}\text { Healthy } \\
\text { students }\end{array}$ & $\begin{array}{l}\text { Car driving } \\
\text { game }\end{array}$ & $\begin{array}{l}3 \text { minutes } \\
\text { gameplay }\end{array}$ & fMRI & $\begin{array}{l}\text { Positive correlations between } \\
\text { the flow experience and brain } \\
\text { activity in regions related to } \\
\text { visual and spatial execution } \\
\text { as well as attentional } \\
\text { processes \& negative } \\
\text { correlations with the DMN's } \\
\text { activity }\end{array}$ \\
\hline
\end{tabular}

$\mathrm{fMRI}=$ functional magnetic resonance imaging; $\mathrm{MRI}=$ magnetic resonance imaging; fNIRS $=$ functional near-infrared spectroscopy; NIRS = near-infrared spectroscopy; ECG = electrocardiography; EDA = electrodermal activity; $\mathrm{tDCS}=$ transcranial direct-current stimulation; FPS = first person shooter; Res = respiration; IFG = inferior frontal gyrus; PFC = prefrontal cortex; $\mathrm{MPFC}=$ medial prefrontal cortex; $\mathrm{AMY}=$ amygdala; $\mathrm{VLPFC}=$ ventrolateral prefrontal cortex; $\mathrm{DLPFC}=$ dorsolateral prefrontal cortex; $\mathrm{PCC}=$ posterior cingulate cortex $\mathrm{DMN}=$ default mode network; $\mathrm{m}=$ male; $\mathrm{f}=$ female 
Table 3 (on next page)

Table 3: Studies on neural correlates of the flow state: neural oscillation investigations 
1

Table 3: Studies on neural correlates of the flow state: neural oscillation investigations

\begin{tabular}{|c|c|c|c|c|c|c|c|}
\hline Ref. & $\underset{\text { subjects }}{\mathbf{N}}$ & $\begin{array}{l}\text { Age } \\
\text { mean/ } \\
\text { range }\end{array}$ & Sample & $\begin{array}{l}\text { Experiment } \\
\text { type }\end{array}$ & Design & Measure & Neural correlates of flow \\
\hline $\begin{array}{l}\text { Kramer et al. } \\
(2007)\end{array}$ & $10(5 f)$ & $18-24$ & $\begin{array}{l}\text { Healthy } \\
\text { students }\end{array}$ & Driving game & Playing trials & $\begin{array}{l}\text { EDA, } \\
\text { EEG }\end{array}$ & $\begin{array}{l}\text { Greater left temporal alpha } \\
\text { predicted performance level }\end{array}$ \\
\hline $\begin{array}{l}\text { Chanel et al. } \\
\text { (2011) }\end{array}$ & $20(7 f)$ & 27 & $\begin{array}{l}\text { Healthy } \\
\text { subjects }\end{array}$ & Tetris game & $\begin{array}{l}5 \text { minutes } \\
\text { Under-challenged } \\
\text { Flow } \\
\text { Over-challenged }\end{array}$ & $\begin{array}{l}\text { EDA, } \\
\text { BP, Res, } \\
\text { T, EEG }\end{array}$ & $\begin{array}{l}\text { Distinct theta \& beta power } \\
\text { between conditions }\end{array}$ \\
\hline $\begin{array}{l}\text { Nacke et al. } \\
(2011)\end{array}$ & $25(\mathrm{~m})$ & $19-38$ & $\begin{array}{l}\text { Healthy } \\
\text { students }\end{array}$ & $\begin{array}{l}\text { FPS game: } \\
\text { Half-Life } 2\end{array}$ & $\begin{array}{l}10 \text { minutes } \\
\text { Under-challenged } \\
\text { Immersion } \\
\text { Flow }\end{array}$ & EEG & $\begin{array}{l}\text { Higher theta \& delta power in } \\
\text { the immersion condition }\end{array}$ \\
\hline $\begin{array}{l}\text { Berta et al. } \\
(2013)\end{array}$ & $22(5 f)$ & 26.3 & $\begin{array}{l}\text { Healthy } \\
\text { students }\end{array}$ & $\begin{array}{l}\text { Plane battle } \\
\text { game }\end{array}$ & $\begin{array}{l}4 \text { minutes } \\
\text { Under-challenged } \\
\text { Flow } \\
\text { Over-challenged }\end{array}$ & EEG & $\begin{array}{l}\text { Lowest mean alpha \& low- } \\
\text { beta in the flow condition }\end{array}$ \\
\hline $\begin{array}{l}\text { Wang \& Hsu } \\
(2014)\end{array}$ & $20(10 f)$ & $19-27$ & $\begin{array}{l}\text { Healthy } \\
\text { students }\end{array}$ & $\begin{array}{l}\text { Computer- } \\
\text { based } \\
\text { instruction }\end{array}$ & $\begin{array}{l}\text { 7-9 minutes } \\
\text { Under-challenged } \\
\text { Flow } \\
\text { Over-challenged }\end{array}$ & EEG & $\begin{array}{l}\text { EEG attention value was } \\
\text { correlated with overall flow } \\
\text { and flow dimensions }\end{array}$ \\
\hline $\begin{array}{l}\text { De Kock } \\
(2014)\end{array}$ & $20(\mathrm{~m})$ & $16-45$ & $\begin{array}{l}\text { Healthy } \\
\text { subjects }\end{array}$ & $\begin{array}{l}\text { Car racing } \\
\text { game: Need } \\
\text { for Speed - } \\
\text { Carbon }\end{array}$ & $\begin{array}{l}\text { Low flow- } \\
\text { performance } \\
\text { High flow- } \\
\text { performance }\end{array}$ & EEG & $\begin{array}{l}\text { Increased low-beta power in } \\
\text { the sensorimotor; low-beta } \\
\text { synchronization between all } \\
\text { cortical connections for high- } \\
\text { flow group }\end{array}$ \\
\hline $\begin{array}{l}\text { Leger et al. } \\
\text { (2014) }\end{array}$ & 36 & - & $\begin{array}{l}\text { Healthy } \\
\text { students }\end{array}$ & $\begin{array}{l}\text { Enterprise } \\
\text { Resource } \\
\text { Planning } \\
\text { software }\end{array}$ & $\begin{array}{l}\text { Under-challenged } \\
\text { Flow } \\
\text { Over-challenged }\end{array}$ & $\begin{array}{l}\text { ECG, } \\
\text { EDA, } \\
\text { EEG }\end{array}$ & $\begin{array}{l}\text { Higher alpha \& lower beta in } \\
\text { the flow condition }\end{array}$ \\
\hline $\begin{array}{l}\text { Wolf et al. } \\
(2015)\end{array}$ & 35 (9f) & $<36$ & $\begin{array}{l}\text { Table- } \\
\text { tennis } \\
\text { players }\end{array}$ & $\begin{array}{l}\text { Motor } \\
\text { imagery } \\
\text { paradigm }\end{array}$ & $\begin{array}{l}7 \text { seconds video } \\
\text { clips }\end{array}$ & EEG & $\begin{array}{l}\text { Positive correlation between } \\
\text { T4-T3 alpha asymmetry \& } \\
\text { flow score in the experts }\end{array}$ \\
\hline
\end{tabular}


27

Table 3: Studies on neural correlates of the flow state: neural oscillation investigations

\begin{tabular}{|c|c|c|c|c|c|c|c|}
\hline Ref. & $\begin{array}{l}\mathbf{N} \\
\text { subjects }\end{array}$ & $\begin{array}{l}\text { Age } \\
\text { mean/ } \\
\text { range }\end{array}$ & Sample & $\begin{array}{l}\text { Experiment } \\
\text { type }\end{array}$ & Design & Measure & Neural correlates of flow \\
\hline $\begin{array}{l}\text { Metin et al. } \\
(2017)\end{array}$ & $20(7 f)$ & $20-35$ & $\begin{array}{l}\text { Healthy } \\
\text { subjects }\end{array}$ & $\begin{array}{l}\text { Ping-pong } \\
\text { game }\end{array}$ & $\begin{array}{l}2 \text { minutes } \\
\text { Under-challenged } \\
\text { Flow }\end{array}$ & EEG & $\begin{array}{l}\text { Greater theta } \& \text { delta power } \\
\text { in the flow condition }\end{array}$ \\
\hline $\begin{array}{l}\text { Katahira et al. } \\
(2018)\end{array}$ & $16(6 f)$ & 21.9 & $\begin{array}{l}\text { Healthy } \\
\text { students }\end{array}$ & $\begin{array}{l}\text { Mental } \\
\text { arithmetic } \\
\text { task }\end{array}$ & $\begin{array}{l}184 \text { seconds } \\
\text { Under-challenged } \\
\text { Flow } \\
\text { Over-challenged }\end{array}$ & EEG & $\begin{array}{l}\text { Increased theta activity in the } \\
\text { frontal areas, moderate alpha } \\
\text { activities in the frontal \& } \\
\text { central areas in the flow } \\
\text { condition }\end{array}$ \\
\hline $\begin{array}{l}\text { Moreno et al. } \\
(2020)\end{array}$ & 1 & 27 & $\begin{array}{l}\text { Expert } \\
\text { gamer }\end{array}$ & Portal game & $\begin{array}{l}45 \text { minutes } \\
\text { gameplay }\end{array}$ & $\begin{array}{l}\text { EDA, } \\
\text { EEG }\end{array}$ & $\begin{array}{l}\text { Increased beta activity during } \\
\text { moments of goal attainment }\end{array}$ \\
\hline
\end{tabular}

ECG = electrocardiography; EEG = electroencephalography; EDA = electrodermal activity; Res = respiration; $\mathrm{BP}=$ blood pressure; $\mathrm{T}=$ temperature; $\mathrm{SD}=$ standard deviation; $\mathrm{m}=$ male; $\mathrm{f}=$ female 


\section{Table 4 (on next page)}

Table 4: Studies on neural correlates of the flow state: dual-task paradigms 
1

Table 4: Studies on neural correlates of the flow state: dual-task paradigms

\begin{tabular}{|c|c|c|c|c|c|c|c|}
\hline Ref. & $\begin{array}{l}\mathbf{N} \\
\text { subjects }\end{array}$ & $\begin{array}{l}\text { Age } \\
\text { mean/ } \\
\text { range }\end{array}$ & Sample & $\begin{array}{l}\text { Experiment } \\
\text { type }\end{array}$ & Design & Measure & Neural correlates of flow \\
\hline $\begin{array}{l}\text { Castellar } \\
\text { et al. (2016) }\end{array}$ & $18(9 f)$ & 28.5 & $\begin{array}{l}\text { Healthy } \\
\text { subjects }\end{array}$ & $\begin{array}{l}\text { Star reaction } \\
\text { game \& Auditory } \\
\text { oddball detection }\end{array}$ & $\begin{array}{l}\text { Under-challenged } \\
\text { Flow } \\
\text { Over-challenged }\end{array}$ & EEG & $\begin{array}{l}\text { Delayed maximal frontocentral } \\
\text { negative deflection after the } \\
\text { response onset in the flow } \\
\text { condition }\end{array}$ \\
\hline $\begin{array}{l}\text { Yun et al. } \\
(2017)\end{array}$ & $29(5 f)$ & 23.5 & $\begin{array}{l}\text { Healthy } \\
\text { subjects }\end{array}$ & $\begin{array}{l}\text { FPS game: Call } \\
\text { of Duty \& } \\
\text { Random beeping } \\
\text { sound }\end{array}$ & $\begin{array}{l}30 \text { minutes } \\
\text { Low challenge/ } \\
\text { High challenge }\end{array}$ & EEG & $\begin{array}{l}\text { Suppressed evoked potential } \\
\text { during self-reported experience } \\
\text { of flow }\end{array}$ \\
\hline $\begin{array}{l}\text { Bombeke } \\
\text { et al. (2018) }\end{array}$ & $18(3 f)$ & 25 & $\begin{array}{l}\text { Healthy } \\
\text { students }\end{array}$ & $\begin{array}{l}\text { FPS game } \\
\text { Counter-Strike: } \\
\text { Global offensive } \\
\text { \& Auditory } \\
\text { oddball detection }\end{array}$ & $\begin{array}{l}8 \text { minutes } \\
\text { Under-challenged } \\
\text { Flow } \\
\text { Over-challenged }\end{array}$ & EEG & $\begin{array}{l}\text { Mid-line P300 amplitude } \\
\text { smaller in VR compared to } \\
\text { playing in 2D in the flow } \\
\text { condition }\end{array}$ \\
\hline $\begin{array}{l}\text { Huskey et al. } \\
(2018)\end{array}$ & $18(\mathrm{~m})$ & - & $\begin{array}{l}\text { Healthy } \\
\text { students }\end{array}$ & $\begin{array}{l}\text { Asteroid Impact } \\
\text { game \& } \\
\text { Secondary } \\
\text { reaction time }\end{array}$ & $\begin{array}{l}2 \text { minutes } \\
\text { Under-challenged } \\
\text { Flow } \\
\text { Over-challenged }\end{array}$ & fMRI & $\begin{array}{l}\text { Higher activity in DLPFC, } \\
\text { SPL, DAI, \& putamen in the } \\
\text { flow condition }\end{array}$ \\
\hline
\end{tabular}

$\mathrm{EEG}=$ electroencephalography; $\mathrm{fMRI}=$ functional magnetic resonance imaging; $\mathrm{ERSP}=$ event-related spectral perturbation; $\mathrm{VR}=$ virtual reality; DLPFC $=$ dorsolateral prefrontal cortex; $\mathrm{SPL}=$ superior parietal lobe; $\mathrm{DAI}=\mathrm{dorsal}$ anterior insula; $\mathrm{m}=$ male; $\mathrm{f}=$ female 